\title{
Liquidity Provision, Interest Rates, and Unemployment*
}

\author{
Guillaume Rocheteau and Antonio Rodriguez-Lopez \\ Department of Economics \\ University of California, Irvine
}

First draft: March 2013

This draft: November 2013

\begin{abstract}
This paper develops a continuous-time model of the public and private provision of liquidity and its relation to unemployment. We extend the Mortensen-Pissarides model of the labor market by adding an over-the-counter (OTC) market where trades are collateralized with claims on firms' profits and public liabilities backed by taxes. As a result, the real interest rate is endogenous and depends on the financing needs of firms, the liquidity needs of OTC-traders, and the public supply of liquidity. When the unemployment is inefficiently high, it is optimal to keep liquidity scarce - thereby reducing the total surplus of OTC-traders - to lower interest rates and promote job creation. In a version of the model with fiat money and nominal bonds, we show that an increase in inflation reduces the real interest rate and the unemployment rate. We study the dynamics of the labor market under scarce liquidity and we introduce heterogeneity across private claims in order to illustrate how a shock to liquidity demand can generate collateral expansion and increase job creation.
\end{abstract}

JEL Classification: D82, D83, E40, E50

Keywords: unemployment, liquidity, interest rates

${ }^{*}$ This paper was prepared for the Carnegie-Rochester-NYU Conference Series on Public Policy on "A Century of Money, Banking, and Financial Instability". We thank Jean-Paul Carvalho, Arvind Krishnamurthy, Nicolas PetroskyNadeau, Edouard Schaal, Mike Woodford, Cathy Zhang, and seminar participants at Bundesbank, UC Riverside, UC Santa Barbara, the University of Melbourne, the University of Paris 2, the 2013 Summer Workshop on Money, Banking, Payments, and Finance at the Federal Reserve Bank of Chicago, and the Philadelphia Search-and-Matching Workshop at the Federal Reserve Bank of Philadelphia for useful discussions and comments. E-mail addresses: grochete@uci.edu and jantonio@uci.edu. 


\section{Introduction}

Since its creation in 1913 a main mission of the Federal Reserve has been to provide and manage the liquidity required to maintain an orderly financial system while achieving maximum employment, price stability, and moderate long term interest rates. ${ }^{1}$ Aggregate liquidity management has become increasingly important due to the reliance of economic agents on safe and liquid assets to secure their various obligations arising from their lending, hedging, and payment activities (BIS, 2001) and due to the relative scarcity of such assets in the global economy (IMF, 2012). ${ }^{2}$ In spite of aggregate liquidity management being a key economic policy, little theoretical work has been done to relate it to macroeconomic outcomes, such as interest rates and unemployment.

The objective of this paper is to fill this void by providing a tractable framework to analyze the joint determination of aggregate liquidity, interest rates, and labor market outcomes. On the positive side we will describe how changes in the supply and demand of liquidity affect interest rates, the supply of jobs, and unemployment. We will identify market mechanisms that mitigate the scarcity of liquidity, and we will describe a liquidity channel through which monetary policy affects the labor market. Moreover, our model can be applied to the recent financial crisis by describing how adverse shocks to the acceptability of private assets as collateral alter the liquidity structure of interest rates and the functioning of the labor market. On the normative side we will study how the optimal provision of liquidity depends on the frictions in the labor market.

From a methodological standpoint we develop a continuous-time model of the labor market that extends the Mortensen-Pissarides framework (MP hereafter) to include a demand and supply of liquidity and endogenous interest rates. We incorporate liquidity considerations by adding an over-the-counter (OTC) market similar to the one in Shi (1995), Trejos and Wright (1995), Duffie, Garleanu, and Pedersen (2005) or Lagos and Wright (2005) in which traders exchange services financed with collateralized loans. This OTC market aims to capture the wholesale financial markets, including repo markets, markets for derivatives, and large-value payment systems (BIS, 2001). ${ }^{3}$ It can also be interpreted as a market where households finance idiosyncratic consump-

\footnotetext{
${ }^{1}$ The Federal Reserve was created by the Federal Reserve Act of 1913 in order to prevent financial panics such as the one in 1907. It was amended in 1977 (Section 2A) to specify the objectives of monetary policy: maximum employment, stable prices, and moderate long-term interest rates. For a description of how the mandates of the Federal Reserve have been shifting over time, see Reinhart and Rogoff (2013).

${ }^{2}$ Safe assets are defined as assets that yield identical real payoffs in each state of the world (IMF, 2012, p.83). As pointed out by the IMF (2012, p.84), there are no truly safe assets. Assets will be considered as safe if they meet certain criteria such as low credit, inflation, exchange rate, and idiosyncratic risks, and high market liquidity. The IMF (2012) documents that sovereign debts account for 45 percent of the total supply of safe assets, while securitized instruments account for 17 percent and corporate debts account for 11 percent.

${ }^{3}$ The Repo market had an average daily trading volume of about $\$ 2.3$ trillion in 2008 (see Gorton and Metrick, 2010). The gross market value of all OTC derivatives contracts at the end of 2012 was $\$ 24.7$ trillion, corresponding to some gross credit exposure of $\$ 3.6$ trillion (BIS, 2013). According to the ISDA (2012) 84 percent of all transactions in OTC derivatives are executed with the support of a collateral agreement, leading to $\$ 3.6$ trillion in collateral backed trades at the end of 2011. According to the ISDA (2010, Figure 1) 97 percent of all credit derivatives were covered
} 
tion opportunities or firms finance investment opportunities with collateralized loans or means of payment.

Two types of assets can serve as collateral in the OTC market: claims on the profits generated by firms, and public assets that are backed by the ability of the policymaker to raise taxes. ${ }^{4}$ When the supply of liquidity is abundant the interest rate is maximum and equal to the rate of time preference and the total surplus in the OTC market is maximized. When the supply of liquidity is scarce - so that OTC-traders' borrowing constraints are binding - the interest rate falls below the rate of time preference. Firms respond to the lower interest rate by opening more jobs so that total market capitalization increases, which raises the private supply of liquidity in accordance with a Tobin (1965) effect.

Our model has a rich set of comparative statics. For instance, regulations that raise collateral requirement for OTC transactions (IMF, 2012, p.95) lead to a reduction in the interest rate, more job creation, and lower unemployment. ${ }^{5}$ Moreover, if private assets are heterogeneous in terms of their pledgeability, such regulatory changes lead to collateral expansion, i.e., assets of lower quality that are subject to lower loan-to-value ratios start being used as collateral.

As another example, a shock that makes firms more productive has the standard effect of raising job creation and reducing unemployment, but this effect is dampened by the increase in the interest rate associated with a more abundant private supply of liquidity. Moreover, along the transition market tightness - the ratio of the number of vacancies to the number of unemployed - overshoots its new steady-state value. Indeed, forward-looking firms anticipate that interest rates will increase over time as the private supply of liquidity increases, and therefore they find it optimal to front-load job openings to take advantage of a temporary low cost of funds.

An increase in the public supply of liquidity, or an open-market sale of bonds, raises the interest rate (by reducing the liquidity premium on private claims) when liquidity is scarce, which slows job creation and reduces the private supply of liquidity. Hence, our model predicts a crowding out of the private liquidity by the public one, in accordance with the evidence from Krishnamurthy and Vissing-Jorgensen (2013). Conversely, an increase in the inflation rate reduces the real interest rate and unemployment.

by collateral arrangements in 2010 while this number was 63 percent for foreign exchange derivatives. The value of transfers on Fedwire in 2012 was equal to $\$ 600$ trillion.

${ }^{4}$ The assumption that some assets play a special role in transactions is consistent with the evidence from Krishnamurthy and Vissing-Jorgensen (2012) according to which both government bonds and highly-rated corporate bonds exhibit convenience yields. According to BIS (2001, p.8) securities accepted as collateral in derivatives markets are limited to government securities. In contrast, in repo transactions a broad range of assets can serve as collateral, including mortgage-backed securities, corporate bonds, and equity. Recently, corporate bonds have also become acceptable for cleared interest swaps.

${ }^{5}$ As an example, the Dodd-Frank Act of 2010 requires a larger fraction of derivatives transactions to be cleared in centralized exchanges with higher collateral requirements. The BIS (2013) provides estimates according to which liquidity regulation and derivatives reforms are expected to increase the demand for high-quality collateral assets by about $\$ 4$ trillion over the next several years. 
From a normative standpoint our model identifies a trade-off between liquidity provision and unemployment. This trade-off arises because of search externalities that can make the unemployment rate inefficiently high. For instance, if the wage is too high relative to workers' contribution to the matching process (as formally defined by the Hosios, 1990, condition), then it is optimal to keep liquidity scarce - thereby reducing the net output of OTC-traders - to lower the cost of financing firms and to promote job creation. This finding suggests that a situation where liquidity needs are not satiated might correspond to a second-best outcome due to trading externalities in the labor market.

We extend our model to describe the effects of a liquidity "crisis" that makes private claims less acceptable as collateral in OTC transactions - for example, due to more acute informational asymmetries. ${ }^{6}$ Such a shock leads to a higher financing cost for firms, a higher rate-of-return differential between private and public liquidity, and higher unemployment. The policymaker can mitigate the adverse effect of this shock by committing to purchase private assets at their pre-crisis price in exchange for public liquidity.

Finaly, in the last section of the paper we assume that the market for loanable funds where firms and OTC-traders meet is subject to search frictions and we introduce linkages in the spirit of Brunnermeier and Pedersen (2009) between the liquidity of the market, i.e., the ease with which firms can get access to loans, and OTC-traders' holdings of liquid assets. If liquidity is abundant, more OTC-traders are willing to participate in the market, which makes it easier for firms to finance job openings. This channel generates a non-monotonic relationship between public liquidity and unemployment, and it implies that an increase in public liquidity does not always crowd out private liquidity.

\section{$1.1 \quad$ Literature}

Our model is related to the literature on unemployment and financial frictions. Wasmer and Weil (2004) extend the MP model to incorporate a credit market with search frictions. ${ }^{7}$ In contrast to our approach, there is no OTC market and no liquidity considerations to endogenize the interest rate. There is also a literature on unemployment and money/liquidity, e.g., Shi (1998), Berentsen, Menzio, and Wright (2011), and Williamson (2013) among others. Our description of the OTC market is similar to their search market with bilateral matches. However, the interest rate faced by firms in these models is exogenous and equal to the rate of time preference since claims on firms' profits are illiquid (i.e., they are not used as collateral). ${ }^{8}$ Moreover, from a methodological point

\footnotetext{
${ }^{6}$ Following the last financial crisis 63 percent of the mortgage-backed securities issued from 2005 to 2007 had been downgraded (IMF, 2012, p.86).

${ }^{7}$ This model was extended and calibrated by Petrosky-Nadeau and Wasmer (2013) and Petrosky-Nadeau (2013).

${ }^{8}$ There are other models of money and frictional labor markets where the goods market is frictionless, i.e., it is not described as a decentralized market with search and bargaining. See, e.g., Cooley and Quadrini (2004) and
} 
of view, our model is written in continuous time, which simplifies the dynamics considerably since the equilibrium is unique. The assumption of claims on capital that serve as collateral in OTC markets is also used in Ferraris and Watanabe (2008), Lagos (2010a, 2011), and Rocheteau and Wright (2013). In those models, however, there is no frictional labor market and no unemployment.

A formalization of OTC markets with bilateral meetings and bargaining has been developed recently in financial economics by Duffie, Garleanu, and Pedersen (2005, 2007), Weill (2007), and Lagos and Rocheteau (2007, 2009), among others. Instead, we adopt the closely related description from monetary theory of Shi (1995) and Trejos and Wright (1995) as it is highly tractable and emphasizes the role of assets (money) as media of exchange, which is the purpose of our analysis.

The results according to which the interest rate falls when private liquidity is scarce and an increase in public liquidity crowds private liquidity out are analogous to those in Lagos and Rocheteau (2008) in the context of a model with fiat money and capital, and to those of Williamson (2012) in a model of costly state verification where private liquidity takes the form of loans to entrepreneurs. We also share a common focus on the provision of public and private liquidity with the corporate finance literature of Holmström and Tirole (1998, 2011). In contrast to these approaches, in our model private liquidity is composed of claims on the profits of Mortensen-Pissarides firms - which allows us to establish connections with the labor market - and the demand for liquidity comes from participants in an OTC market who are anonymous and lack commitment.

There are versions of the MP model where the interest rate is endogenous. Typically, this is achieved by assuming that households are risk-averse and accumulate assets to smooth their consumption over time. For instance, Bean and Pissarides (1993) introduce a search-labor market into an overlapping-generations economy, while Andolfatto (1996) and Merz (1995) incorporate similar frictions into a real business cycle model with perfect insurance. Uren (2013) describes a continuous-time economy similar to the one in Andolfatto (1996) and Merz (1995) where households endowed with CARA preferences insure themselves against employment shocks by accumulating risk-free assets. Our model differs from these approaches in that households or workers are riskneutral and have no need for consumption smoothing. The demand for liquid assets comes entirely from OTC traders, and the supply of liquidity is composed of both public and heterogeneous private assets. Moreover, we characterize analytically both steady-state and non-stationary equilibria.

Woodford (1990) formalized the role of government debt to alleviate liquidity constraints in the context of an economy with alternating endowments. A related recent literature derives a demand for safe/liquid assets in the context of overlapping-generations economies. Caballero and Farhi (2013) analyze the effectiveness of non-conventional monetary policies (e.g. quantitative easing) in such an environment while Gourinchas and Jeanne (2012) argue that bubbles can be prevented with

Lehmann (2012). 
a large enough supply of safe assets. Gorton and Ordoñez (2013) highlight the role of government bonds during times of crisis when private assets become information-sensitive. In contrast to these papers, we explicitly model the labor market and relate it to the private provision of liquidity, which varies with the entry of firms.

\section{The environment}

Time is continuous and indexed by $t \in \mathbb{R}_{+}$. There are three categories of agents: a large measure of firms, a unit measure of workers, and a unit measure of OTC-traders. There are two types of perishable goods: a good that is consumed by all agents and that is taken as the numéraire, and a service that is produced and consumed by OTC-traders only.

Workers are endowed with one indivisible unit of labor per unit of time, they are risk-neutral, and they discount future consumption at rate $\rho>0$, i.e., their lifetime expected utility is

$$
\mathbb{E} \int_{0}^{\infty} e^{-\rho t} d C(t)
$$

where $C(t)$ is their cumulative consumption of the numéraire good. ${ }^{9}$ A firm is a technology to produce the numéraire good using a worker's indivisible labor as input.

OTC-traders exchange services in an over-the-counter market, with bilateral matching and bargaining. ${ }^{10}$ The lifetime expected utility of an OTC-trader is

$$
\mathbb{E}\left\{\sum_{n=1}^{+\infty} e^{-\rho T_{n}}\left\{f\left[y\left(T_{n}\right)\right]-x\left(T_{n}\right)\right\}+\int_{0}^{\infty} e^{-\rho t} d C(t)\right\},
$$

where the first term accounts for the utility from OTC trades, while the second term accounts for the utility from net consumption of the numéraire good. The process $\left\{T_{n}\right\}$ is Poisson with arrival rate $\alpha>0$, and indicates the times at which the trader is matched bilaterally with another trader. Upon a bilateral match being formed, a trader is chosen at random to be either a supplier

\footnotetext{
${ }^{9}$ The path for consumption is composed of flows - in which case $C(t)$ admits a density, $c(t)$ - and lumps - in which case $C\left(t^{+}\right)-C\left(t^{-}\right)>0$. A similar cumulative consumption process is assumed in the continuous-time models of OTC trades of Duffie, Garleanu, and Pedersen (2005).

${ }^{10}$ Our description of the OTC market is similar to the one used in monetary theory following Shi (1995) and Trejos and Wright (1995). According to this model the demand for liquidity originates from agents who receive random and infrequent opportunities to consume (see also Lagos and Wright, 2005 and Alvarez and Lippi, 2013). It would be straightforward to reinterpret the demand for liquidity as coming from firms with random investment opportunities (see, e.g., Holmström and Tirole, 2011, or Kiyotaki and Moore, 2005). We favor the interpretation of an OTC market for derivatives, such as the market for credit default swaps or interest rate swaps where risk-sharing services are traded for collateralized loans, or repurchase agreements. Indeed, the IMF (2012) argues that high-quality collateral is critical to many transactions in OTC markets, and the ultimate demanders of collateral include hedge funds, brokers-dealers, and banks. See Li, Rocheteau, and Weill (2012, Appendices G and H) for an explicit formalization. See, also, Koeppl, Monnet, and Temzelides (2008) for an application to wholesale payment and settlement systems. Alternatively, we could have described an OTC market where agents reallocate their asset holdings, as in Duffie, Garleanu, and Pedersen (2005), subject to liquidity constraints. See, e.g., Geromichalos and Herrenbrueck (2013). For our purpose the Shi-Trejos-Wright approach is more tractable.
} 


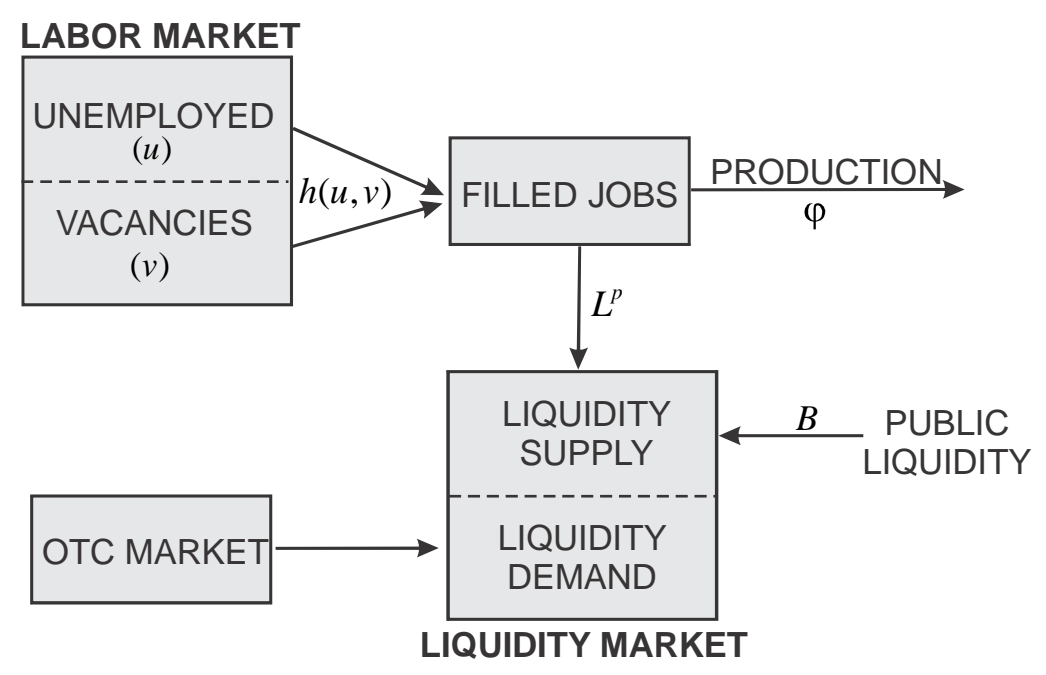

Figure 1: Sketch of the model

of services or a user of services. The utility from consuming $y$ units of services is $f(y)$, where $f$ is strictly concave, $f(0)=0, f^{\prime}(0)=+\infty$, and $f^{\prime}(\infty)=0 .{ }^{11}$ The disutility from producing $x$ units of services is $x$. For a given trader, either $y\left(T_{n}\right)>0$ (he is a user of services with probability $1 / 2$ ) or $x\left(T_{n}\right)>0$ (he is a supplier with probability $1 / 2$ ). For two traders in a match, feasibility requires that the consumption of the user, $y\left(T_{n}\right)$, is no greater than the production of the supplier, $x\left(T_{n}\right)$.

At all $t \notin\left\{T_{n}\right\}_{n=1}^{\infty}$ OTC-traders can consume and produce the numéraire good, $d C(t) \in \mathbb{R}$. We allow for the production/consumption of discrete quantities. The technology to consume/produce the numéraire good is not available at times $\left\{T_{n}\right\}$ when traders are matched and the numéraire good is not storable. ${ }^{12}$ Moreover, unsecured promises to repay loans are not credible due to lack of commitment and monitoring. These assumptions imply that the buyer of the services in the OTC market cannot finance $y$ with the production of the numéraire good, thereby creating a need for liquid assets from OTC market participants.

Workers and firms are matched bilaterally in a labor market with search-matching frictions. The flow of hires is equal to $h(u, v)$, where $u$ denotes the measure of unemployed workers (which is also equal to the unemployment rate) and $v$ denotes the measure of vacancies. The matching function, $h$, has constant returns to scale, is strictly concave with respect to each of its arguments, and satisfies Inada-like conditions. The job finding rate of a worker is $p \equiv h(u, v) / u=h(1, \theta)$ where $\theta \equiv v / u$ is

\footnotetext{
${ }^{11}$ Alternatively, one could interpret, $f(y)$, as a production of the numéraire good based on the use of $y$ units of input factor. In that case, the producer cannot transfer some of the output directly to the supplier of the input, i.e., the output must be sold in the competitive goods market.

${ }^{12}$ Following Atkeson, Eisfeldt, and Weill (2013), one can think of OTC-traders as individual traders part of large financial institutions within which assets can be reallocated. This interpretation is similar to the one of the large households that pool money holdings in the monetary theory of Shi (1997). According to this interpretation, OTCtraders face trading limits determined by the amount of liquid assets that has been allocated to them by their institution.
} 
called labor market tightness. The vacancy filling rate of a firm is $q \equiv h(u, v) / v=h\left(\theta^{-1}, 1\right)$. Each match composed of a worker and a firm produces a constant flow of output equal to $\varphi>0$. A match is destroyed with Poisson arrival rate $\delta>0$. The wage of an employed worker is $w \in(0, \varphi)$. With no loss in generality we set the income of the unemployed to 0 .

In order to fill a job a firm must open a vacancy. The flow cost of advertising a vacancy in terms of the numéraire good is $\gamma>0$. Firms' recruiting expenses are paid for by OTC-traders in exchange for the ownership in the future profits of the firm (or, equivalently, by households or firms who then sell claims on filled jobs' revenue to OTC-traders in a competitive asset market). OTC-traders can fully diversify their portfolio of firms - e.g., through mutual funds or by the securitization of large pools of assets - and turn private claims into safe and liquid assets. ${ }^{13}$ Claims on firms' revenue are liquid in the sense that they are not subject to informational asymmetries and as a result they can be used as collateral in OTC trades. Later we will consider an extension where these claims are only partially acceptable as collateral.

There is a supply, $B$, of pure discount, government bonds that pay one unit of numéraire good according to a Poisson process with arrival rate $\varkappa>0$, i.e., $1 / \varkappa$ is a measure of the maturity of the bonds. The terminal payment of bonds is financed through lump-sum taxation. ${ }^{14}$ Government bonds are not counterfeitable, they are perfectly divisible, and they can serve as collateral in the OTC market. The present discounted value of a bond is $\varkappa /(r+\varkappa)$, where $r$ is the rate of return on liquid assets (both public and private). We will consider the limit when $\varkappa$ tends to infinity. The price of such a short-term bond is one and the public supply of liquidity in terms of the numéraire good is $B .{ }^{15}$

\section{Equilibrium}

In the following we focus on steady-state equilibria where unemployment, market tightness, and the real interest rate are constant over time. We take the real wage as exogenous (we endogenize it in the Appendix). We will analyze in turn the supply of private liquidity arising from the creation

\footnotetext{
${ }^{13}$ Some authors (e.g., Krishnamurthy and Vissing-Jorgensen, 2012; IMF, 2012) have argued that "safety" is a key characteristic of a liquid asset. Gorton, Lewellen, and Metrick (2012) define safe assets as "assets that are either directly or indirectly used in an information-insensitive fashion, i.e. as money". Safe debt includes money market mutual fund shares, commercial paper, securitized debt, and high-grade financial-sector corporate debt, among other securities. While we do not have an explicit intermediation sector, one interpetation is that claims on firms' profits are made liquid by a mutualization of risks engineered by financial intermediaries. See Williamson (2012) for a more detailed description of the intermediation sector.

${ }^{14} \mathrm{We}$ assume here that the government can enforce the repayment of tax liabilities but it does not have the technology to monitor and enforce all private contracts. Also, by assuming lump-sum taxes we ignore a possible trade-off between the distortions induced by taxation and liquidity provision. For an analysis of this trade-off see, e.g., Angeletos, Collard, Dellas, and Diba (2013) and Gorton and Ordoñez (2013).

${ }^{15}$ Notice that $B$ could also include private liquid assets in fixed supply, such as land (see, e.g., Rocheteau and Wright, 2013). Also, one can interpret $B<0$ as a situation where the government withdraws liquidity from the economy, e.g., by holding private liquid assets.
} 
of firms, the demand of liquidity by OTC-traders, and the determination of the real interest rate to clear the market for liquid assets.

\subsection{Supply of liquidity}

We first determine the aggregate capitalization of firms as a function of the interest rate, $r$. This capitalization will determine the amount of private liquidity available to OTC-traders. All claims on firms' profits are made safe and liquid through (costless) mutualization and securitization, and as a result are part of the liquidity of the economy. (We relax this assumption in Sections 6 and 7.)

Let $V_{F}$ denote the discounted sum of the profits of a firm. It solves the flow Bellman equation:

$$
r V_{F}=\varphi-w-\delta V_{F}
$$

or, equivalently,

$$
V_{F}=\frac{\varphi-w}{r+\delta} .
$$

From (1) the expected rate of return of a firm, $r$, is equal to the inverse of the price-earning ratio, $(\varphi-w) / V_{F}$, net of the job destruction rate, $\delta$. Equivalently, from (2) the value of the firm is the discounted sum of its instantaneous profits, $\varphi-w$, where the effective discount rate is the real interest rate augmented with the job destruction rate. From (2) $r>-\delta$ in order to guarantee a positive value to firms.

New firms are financed as long as the flow cost of opening a vacancy, $\gamma$, is no greater than the flow expected value of a vacancy, which is the product of the vacancy filling rate and the value of a filled job, $q(\theta) V_{F}$. The vacancy filling rate decreases with market tightness, i.e., $q^{\prime}(\theta)<0$. From the definition of $V_{F}$ in (2), free entry implies

$$
\frac{\gamma}{q(\theta)}=\frac{\varphi-w}{r+\delta}
$$

For given $r$, (3) determines a unique $\theta>0$. Moreover, as the real interest rate increases, the value of a filled job declines, which reduces the incentives to fund new firms, i.e., $\theta$ decreases with $r$.

In a steady state the number of jobs destroyed per unit of time is equal to the number of jobs created, i.e., $n \delta=p(1-n)$, where $n$ represents the measure of filled jobs. Solving for $n$ we obtain

$$
n=\frac{p(\theta)}{\delta+p(\theta)}
$$

The measure of firms increases with $\theta$, where $\theta$ is given by (3). The private provision of liquidity corresponds to the total capitalization of firms defined as $L^{p}=n V_{F}$. Using that $V_{F}=\gamma / q(\theta)$, it is equal to

$$
L^{p}(r)=\frac{\gamma \theta(r)}{\delta+p[\theta(r)]}=\frac{\gamma}{\delta / \theta(r)+q[\theta(r)]},
$$


where $\theta(r)$ is a decreasing function of $r$ and hence $L^{p \prime}<0$. As the real interest rate increases the value of filled jobs decreases (from (2)) and the number of firms decreases, (from (3) and (4)). As a consequence, the private supply of liquidity shrinks. Moreover, $L^{p}(-\delta)=+\infty$ since the discounted sum of a firm's profits becomes unbounded as $r$ approaches $-\delta$, and $L^{p}(\rho) \in(0,+\infty)$, i.e., there is a positive but finite supply of liquidity when the interest rate is equal to the rate of time preference. (As we will see later the real interest rate cannot be larger than $\rho$ since otherwise the asset demand from households and OTC traders would be unbounded.)

The sum of the private supply of liquidity, $L^{p}$, and the public supply of liquidity, $B$, is the total liquidity supply of the economy, denoted $L^{s}(r) \equiv L^{p}(r)+B$. The curve $L^{s}$ is represented graphically in Figure 3 in the case where $B=0$.

\subsection{Demand for liquidity}

We now turn to the demand for liquidity by OTC-traders. Let $W\left(a_{0}\right)$ denote the lifetime expected discounted utility of an OTC-trader holding $a_{0}$ units of liquid assets (claims on firms' profits and government bonds). The OTC-trader's problem can be written recursively as follows:

$$
\begin{gathered}
W\left(a_{0}\right)=\max _{a(t), c(t), k,\left\{\Delta_{j}, t_{j}\right\}}\left\{\mathbb{E} \int_{0}^{T_{1}} e^{-\rho t} c(t) d t+\sum_{j=1}^{k} e^{-\rho t_{j}} \Delta_{j} \mathbb{I}_{\left\{t_{j} \leq T_{1}\right\}}+e^{-\rho T_{1}} Z\left[a\left(T_{1}\right)\right]\right\} \\
\text { s.t. } \dot{a}=r a-c-\Upsilon \text { for all } t \neq t_{j} \\
\Delta_{j} \equiv C\left(t_{j}^{+}\right)-C\left(t_{j}^{-}\right)=-\left[a\left(t_{j}^{+}\right)-a\left(t_{j}^{-}\right)\right] \text {for all } j=1, \ldots, k \\
a(0)=a_{0},
\end{gathered}
$$

where $T_{1}$ is the random time at which the trader is matched with another trader, and $\mathbb{I}_{\left\{t_{j} \leq T_{1}\right\}}$ is an indicator function that is equal to one if $t_{j} \leq T_{1}$ (and zero otherwise). According to (6) the trader chooses his asset holdings, $a(t)$, and consumption path, $c(t)$ and $\Delta_{j}$, so as to maximize his discounted cumulative consumption until $T_{1}$ plus the present continuation value of a trading opportunity in the OTC market at time $T_{1}$ with $a\left(T_{1}\right)$ units of liquid assets, $Z\left[a\left(T_{1}\right)\right]$. From (8), the second term on the right side of (6) represents lumpy consumption (production if $\Delta_{j}<0$ ) financed by discrete jumps in asset holdings. The trader chooses both the sizes of these discrete adjustments, $\Delta_{j}$, and their timing, $t_{j}$, with $k$ denoting the number of adjustments. Equation (7) is a budget identity according to which the trader produces the numéraire good to finance the change in asset holdings $(\dot{a})$ and taxes $(\Upsilon)$ net of the return on those assets $(r a)$.

From the assumption that $T_{1}$ is exponentially distributed with arrival rate $\alpha$, the problem (6)-(7) can be reexpressed more compactly as

$$
W\left(a_{0}\right)=\max _{a(t), c(t), k,\left\{\Delta_{j}, t_{j}\right\}} \int_{0}^{\infty} e^{-(\alpha+\rho) t}\{c(t)+\alpha Z[a(t)]\} d t+\sum_{j=1}^{k} e^{-(\alpha+\rho) t_{j}} \Delta_{j} .
$$


From (10) the OTC-trader's problem is equivalent to one where his discount rate is $\alpha+\rho$ and his instantaneous utility is $c+\alpha Z(a)$. The current-value Hamiltonian is $H(c, a, \xi)=c+\alpha Z(a)+$ $\xi(r a-c-\Upsilon)$, where $\xi$ denotes the costate variable. We assume, and verify later, that $Z$ is a concave function. A solution to $\max _{c} H(c, a, \xi)$ exists if $\xi=1$ for all $t$ so that the value function is linear with $W^{\prime}(a)=1 .{ }^{16}$ The necessary condition for the costate variable, $(\alpha+\rho) \xi=\partial H / \partial a+\dot{\xi}$, gives the following demand for liquid assets:

$$
Z^{\prime}(a)=1+\frac{\rho-r}{\alpha}
$$

The left side of (11) is the benefit to a trader from holding an additional unit of asset. The right side of (11) is the cost of purchasing assets worth one unit of numéraire good augmented by the expected holding cost of the asset until the next trading opportunity in the OTC market. This holding cost is equal to the difference between the rate of time preference and the real interest rate, $\rho-r$, multiplied by the average time until the next trading opportunity in the OTC market, $\mathbb{E}\left[T_{1}\right]=1 / \alpha$. From (11) the choice for $a$ is independent from $a_{0}$, which implies that asset holdings jump instantly to their desired value, $a^{*}$, irrespective of the initial asset holdings of the trader. ${ }^{17}$ Formally, there is a single adjustment of asset holdings, $k=1$, which occurs as soon as the trader access the market for liquid assets, $t_{1}=0$, and the size of the adjustment is the difference between the optimal asset holdings and the initial asset holdings, $a^{*}-a_{0}$.

Alternatively, the value function of the OTC-trader holding a portfolio, $a$, until a match occurs (at time $T_{1}$ ) solves the following flow Bellman equation:

$$
\rho W(a)=r a-\Upsilon+\alpha[Z(a)-W(a)]
$$

According to the right side of (12) the trader enjoys the flow return on his liquid assets, $r a$, and with instantaneous probability, $\alpha$, he enters a match with $a$ units of asset. The trader chooses his asset holdings, $a^{*}$, to maximize $W(a)-a$, i.e.,

$$
a^{*} \in \arg \max _{a \geq 0}[W(a)-a]=\arg \max _{a \geq 0}\{(r-\rho-\alpha) a+\alpha Z(a)\} .
$$

It can be checked that the solution to (13) coincides with (11).

The expected lifetime utility of an OTC-trader holding $a$ units of liquid assets at time $T_{1}$ - when a bilateral match occurs - is $Z(a)=\left[Z^{b}(a)+Z^{s}(a)\right] / 2$, where $Z^{b}$ is the value of being a buyer of the OTC services and $Z^{s}$ is the value of being a seller of those services. By assumption the trader has an equal chance of being a buyer or a seller.

\footnotetext{
${ }^{16}$ A treatment of optimal control problems with jumps in the state variable is provided by Seierstad and Sydsaeter (1987, Chapter 3, Theorem 7).

${ }^{17}$ The result according to which agents' choice of asset holdings when entering the competitive asset market is independent from their asset holdings when leaving the OTC market is also present in the discrete-time monetary model of Lagos and Wright (2005) and the continuous-time model of OTC trades of Lagos and Rocheteau (2009).
} 
A contract in the OTC market is a pair, $(y, \tau)$, that specifies a production of services, $y$, by the seller in exchange for a transfer of assets, $\tau$. The contract can be interpreted literally as one where the buyer is paying with assets so that the trade is final. Alternatively, the contract can be viewed as a collateralized loan where the buyer promises to repay $\tau$ units of numéraire as soon as he exits the OTC market, and the repayment of the loan is secured by the deposit of $\tau$ units of liquid assets. ${ }^{18}$

For simplicity, we assume that the buyer sets the terms of the OTC contract unilaterally, and the seller simply accepts or rejects this contract. ${ }^{19}$ Suppose that the buyer holds $a^{b}$ units of liquid assets while the seller holds $a^{s}$. The buyer's problem is then:

$$
\begin{gathered}
Z^{b}\left(a^{b}\right)=\max _{y, \tau}\left\{f(y)+W\left(a^{b}-\tau\right)\right\} \\
\text { s.t. } Z^{s}\left(a^{s}\right)=-y+W\left(a^{s}+\tau\right) \geq W\left(a^{s}\right) \\
\tau \in\left[-a^{s}, a^{b}\right] .
\end{gathered}
$$

According to (14) the buyer chooses his consumption of OTC services, $y$, and a transfer of liquid assets to the seller, $\tau$, in order to maximize the utility from the OTC services plus his continuation value with $a^{b}-\tau$ liquid assets. The inequality (15) is a participation constraint for the seller. It says that the utility of the seller from accepting the trade, the left side of (15), must be equal or greater than his utility from rejecting the trade, the right side of (15). By accepting the trade the seller must produce $y$ units of service at a cost equal to $y$ but he accumulates $\tau$ units of liquid assets. Finally, (16) is a feasibility condition stating that the transfer of assets from the buyer to the seller cannot be greater than the assets held by the buyer, and similarly the seller cannot transfer more assets than he holds - obviously, incentive feasibility will imply $\tau \geq 0$.

Using the linearity of $W$, the problem (14)-(16) reduces to

$$
\max _{y, \tau}\{f(y)-\tau\} \quad \text { s.t. }-y+\tau \geq 0 \text { and } \tau \in\left[-a^{s}, a^{b}\right] .
$$

The solution is $y=\tau=y^{*}$, where $f^{\prime}\left(y^{*}\right)=1$, if $a^{b} \geq y^{*}$; otherwise, $y=\tau=a^{b}$. So provided that the buyer holds enough liquid assets he can ask for the surplus-maximizing level of services, $y^{*}$, and he uses a fraction of his assets to collateralize the trade. If the buyer does not hold enough assets - he is liquidity constrained - then he will commit all his assets to purchase the maximum amount of services that the seller is willing to produce in exchange for those assets.

\footnotetext{
${ }^{18}$ One can find these different interpretations in the monetary search literature. For instance, in Lagos and Rocheteau (2008) agents use capital as means of payment in bilateral matches while in Ferraris and Watanabe (2008) capital is used to collateralize loans. These different interpretations are also discussed in Lagos (2011).

${ }^{19}$ It would be straightforward to generalize this trading protocol to give some bargaining power to the seller, e.g., by using the generalized Nash solution or the proportional bargaining solution. These generalizations would not affect the main insights of our model.
} 
Using the solution to the bargaining problem we rewrite the value functions of the OTC-trader as follows:

$$
\begin{aligned}
Z^{b}(a) & =\max _{y \leq a}\{f(y)-y\}+W(a) \\
Z^{s}(a) & =W(a) \\
Z(a) & =\frac{1}{2} \max _{y \leq a}\{f(y)-y\}+W(a) .
\end{aligned}
$$

From (18) the value of the buyer is equal to the whole surplus of the match, $f(y)-y$, augmented by the continuation value of the trader, $W(a)$. From (19) the seller receives no surplus from a match. From (20) the expected value to a trader upon being matched is half of the match surplus plus his continuation value, $W(a)$. As a result, the value of an additional unit of liquid asset when matched, before the trader's role as buyer or seller is realized, is

$$
Z^{\prime}(a)=\frac{\left[f^{\prime}(a)-1\right]^{+}}{2}+1
$$

where $[x]^{+}=\max \{x, 0\}$. With probability $1 / 2$ the trader is a buyer, in which case an additional unit of asset allows him to increase his surplus by $f^{\prime}(y)-1$. Using the fact that $y=a$ whenever $a \leq y^{*}$, and $y=y^{*}$ otherwise, (21) implies that $Z(a)$ is strictly concave for all $a<y^{*}$ and it is linear for all $a \geq y^{*}$. The trader's value functions are represented graphically in Figure 2 .

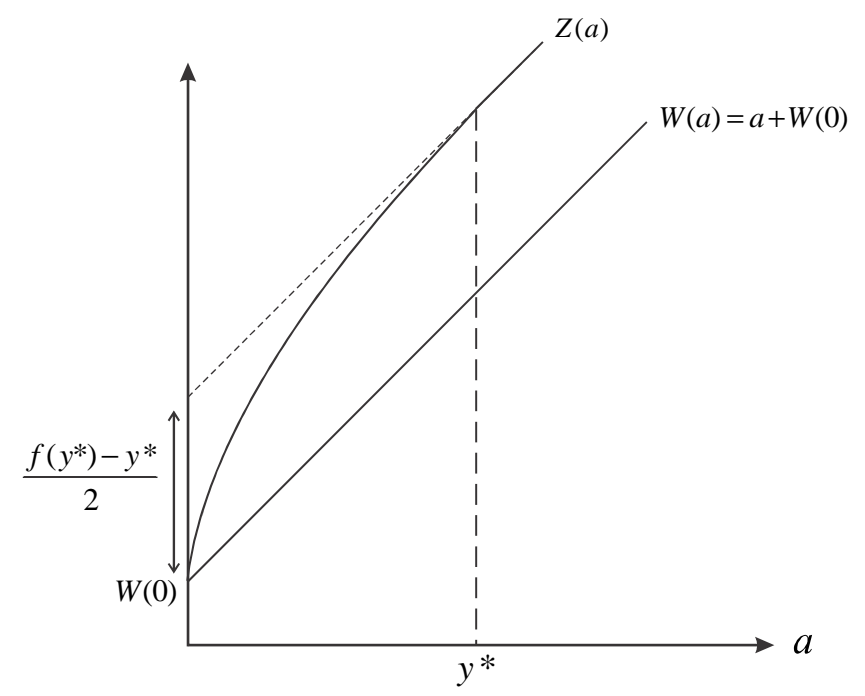

Figure 2: Value functions of the OTC-trader

Denote $\sigma=\alpha / 2$ the Poisson arrival rate at which an OTC-trader gets matched as a buyer. From (11) and (21), the choice of liquid assets of the trader solves

$$
f^{\prime}(a)=f^{\prime}(y)=1+\frac{\rho-r}{\sigma} .
$$


The first equality in (22) captures the fact that $y=a$ when the trader is liquidity constrained. The second equality indicates that the trader accumulates liquid assets up to the point where the marginal surplus of an OTC trade, $f^{\prime}(y)-1$, is equal to the expected holding cost of the asset, $(\rho-r) / \sigma$. So (22) defines the trader's individual demand for liquid assets, $a^{d}=f^{\prime-1}[1+(\rho-r) / \sigma]$ for all $r<\rho$. If $r=\rho$, liquidity is costless to hold so that traders hold $a^{d} \geq y^{*}$. From (12) and (20), the value of an OTC trader is

$$
W(a)=a+\frac{\max _{y}\{-(\rho-r) y+\sigma[f(y)-y]\}-\Upsilon}{\rho} .
$$

From (23) the lifetime expected utility of the OTC trader is equal to his initial wealth plus the discounted sum of his expected surpluses in the OTC market net of taxes and the cost of holding liquid assets to finance OTC trades.

The liquidity demand correspondence is obtained by aggregating the demands for liquid assets across all OTC-traders, i.e.,

$$
\begin{aligned}
L^{d}(r) & =\left\{f^{\prime-1}\left(1+\frac{\rho-r}{\sigma}\right)\right\} \text { if } r<\rho \\
& =\left[y^{*},+\infty\right) \text { if } r=\rho .
\end{aligned}
$$

As long as liquidity is costly to hold, $r<\rho$, OTC-traders hold less than is necessary to buy $y^{*}$ and the demand correspondence is a singleton. The aggregate demand for liquidity declines with the holding cost of assets, $(\rho-r) / \sigma$, and thus, it declines with $\rho-r$ and it increases with $\sigma$. Hence, as the real interest rate increases traders hold more liquidity. If $r=\rho$, then the aggregate demand for liquidity corresponds to any value above $y^{*}$.

\subsection{Clearing the market for liquidity}

The clearing condition for the market for liquidity is

$$
L^{s}(r) \equiv B+L^{p}(r) \in L^{d}(r)
$$

The left side of (26) is the sum of the public and private supply of liquidity. The right side of (26) is the demand for liquidity. In Figure 3 we represent both sides in the absence of public liquidity, $B=0$. The demand for liquidity is upward sloping, it approaches 0 when $r$ tends to $-\infty$, and it is indeterminate above $y^{*}$ when $r=\rho$. The supply of liquidity is downward sloping, it is equal to some finite quantity when $r=\rho$, and it becomes infinite when $r$ approaches $-\delta$. It can be seen on Figure 3 that there is a unique intersection, denoted $\left(L^{e}, r^{e}\right)$, of the demand and supply of liquidity. The introduction of public liquidity shifts the $L^{s}$ curve to the right.

Definition 1 A steady-state equilibrium is a triple, ( $\theta, y, r)$, that solves (3), (22), and (26). 


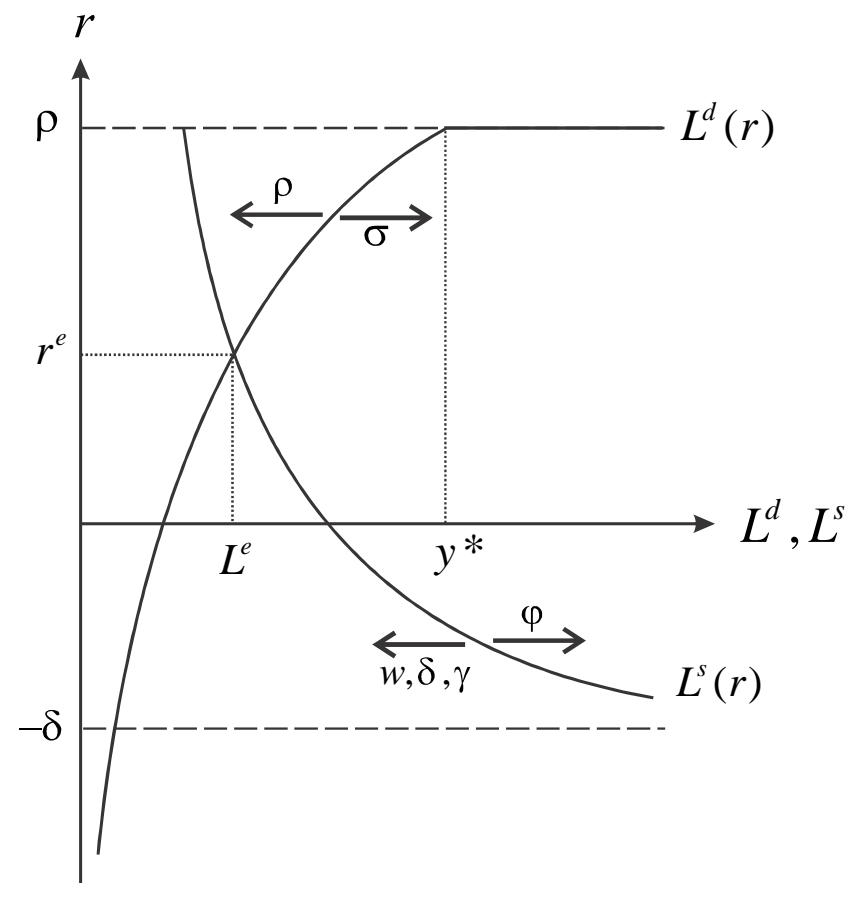

Figure 3: The market for liquidity

From the discussion above and Figure 3 there is a unique $r$ that clears the market for liquidity. Hence, $\theta$ is uniquely determined from (3) and $y$ is uniquely determined from (22). So the steadystate equilibrium is unique. In order to characterize steady-state equilibria we distinguish two cases. In the first case liquidity is abundant in the sense that the demand for liquidity is satiated, i.e., $y=y^{*}$ and $r=\rho$. Graphically, the supply of liquidity intersects the demand in its horizontal part. This type of equilibrium requires $B+L^{p}(\rho) \geq y^{*}$, i.e.,

$$
B+\frac{\hat{\theta} \gamma}{\delta+p(\hat{\theta})} \geq y^{*},
$$

where $\hat{\theta}$ solves

$$
\frac{\gamma}{q(\hat{\theta})}=\frac{\varphi-w}{\rho+\delta}
$$

Condition (27) holds if firms' instantaneous profits, $\varphi-w$, are large, the cost of creating jobs, $\gamma$, is low, or the separation rate, $\delta$, is low. From (28) market tightness is determined as in the MP model where the real interest rate is the rate of time preference. In this regime the net output in the OTC market is maximum and equal to $\sigma\left[f\left(y^{*}\right)-y^{*}\right]$ and an increase in the supply of liquidity has no effect on the real interest rate and the labor market.

Next, we consider the case in which liquidity is scarce so that the borrowing constraints of traders in the OTC market are binding, i.e., $B+L^{p}(\rho)<y^{*}$. This case corresponds to the graphical representation in Figure 3 where the equilibrium interest rate is less than the rate of time 
preference, $r<\rho$. From (3) and (24) the pair of endogenous variables, $(\theta, r)$, is determined jointly by the following two equations:

$$
\begin{aligned}
B+\frac{\theta \gamma}{\delta+p(\theta)} & =f^{\prime-1}\left(\frac{\rho-r}{\sigma}+1\right) \\
r & =\frac{(\varphi-w) q(\theta)}{\gamma}-\delta .
\end{aligned}
$$

The first condition gives a positive relationship between $\theta$ and $r$ while the second relationship gives a negative relationship between $r$ and $\theta$. The comparative statics are represented graphically in Figure 3 by arrows indicating how an increase in a parameter shifts the liquidity demand and supply curves, and they are summarized in Table 1. Each cell indicates the sign of the partial derivative of the endogenous variable in the row with respect to the exogenous variable in the column.

\begin{tabular}{|c||c|c|c|c|c|c|c|}
\hline$\frac{\text { exogenous } \rightarrow}{\text { endogeneous } \downarrow}$ & $\varphi$ & $w$ & $\delta$ & $\gamma$ & $\sigma$ & $\rho$ & $B$ \\
\hline \hline$r$ & + & - & - & - & - & + & + \\
\hline$\theta$ & + & - & - & - & + & - & - \\
\hline$u$ & - & + & + & + & - & + & + \\
\hline$y$ & + & - & - & - & + & - & + \\
\hline
\end{tabular}

Table 1: Comparative statics

Consider an increase in firm's productivity, $\varphi$. Firms become more valuable and the supply of liquidity increases, graphically $L^{s}$ shifts to the right. As a consequence, both $r$ and $\theta$ are higher, and the unemployment rate, $u$, is lower. OTC-traders hold more liquidity, which raises the amount of services that are produced and exchanged, $y$, and creates a positive spillover from the real economy to the OTC sector. Differentiating (29) and (30), the elasticity of market tightness with respect to productivity is

$$
\frac{d \theta / \theta}{d \varphi / \varphi}=\left\{-\frac{\sigma f^{\prime \prime}(y)\left(L^{p}\right)^{2}}{\varphi}\left[1-\eta(\theta)+\frac{\delta}{p(\theta)}\right]+[1-\eta(\theta)] \frac{\varphi-w}{\varphi}\right\}^{-1},
$$

where $\eta(\theta) \equiv \theta p^{\prime}(\theta) / p(\theta) \in[0,1]$ is the elasticity of the matching function. In contrast, when liquidity is abundant,

$$
\frac{d \theta / \theta}{d \varphi / \varphi}=\frac{\varphi}{[1-\eta(\theta)](\varphi-w)}
$$

The comparison of (31) and (32) shows that for given $(\varphi-w) / \varphi$ the elasticity of market tightness with respect to productivity is lower when liquidity is scarce due the endogenous response of the interest rate. Thus, the scarcity of liquid assets dampens the effects of a productivity shock on the labor market. ${ }^{20}$

\footnotetext{
${ }^{20}$ If OTC activities were labor intensive, then the positive spillover of the productivity shock could lead to higher employment in the OTC sector.
} 
An increase in the wage, $w$, separation rate, $\delta$, cost of opening a vacancy, $\gamma$, have the opposite effects on labor market outcomes and real interest rate as those stemming from an increase in productivity. As shown in Figure 3, an increase in any of these parameters shifts the private supply of liquidity to the left. For each level of $r \leq \rho$, the private supply of liquidity declines because each firm becomes less valuable when either $w$ or $\delta$ increase, and because the steady-state number of jobs declines when $\gamma, w$, or $\delta$ increase.

An increase in $\sigma$, the frequency of meetings between OTC-traders, generates a higher demand for liquid assets. For instance, changes in regulation for OTC trades-e.g., the move of OTC derivatives contracts to central counterparties - might require a larger set of transactions to be secured with collateral. ${ }^{21}$ Graphically, the demand for liquidity, $L^{d}$, in Figure 3 moves to the right. The price of liquid assets increases, the real interest rate declines, market tightness increases, and unemployment declines. Moreover, the increase in the private provision of liquidity due to the lower real interest rate allows traders to exchange more services, i.e., $y$ increases. Therefore, a reform that imposes more stringent requirements on OTC trades to secure payments generates cheaper financing conditions for the real economy, thereby stimulating the private provision of liquidity.

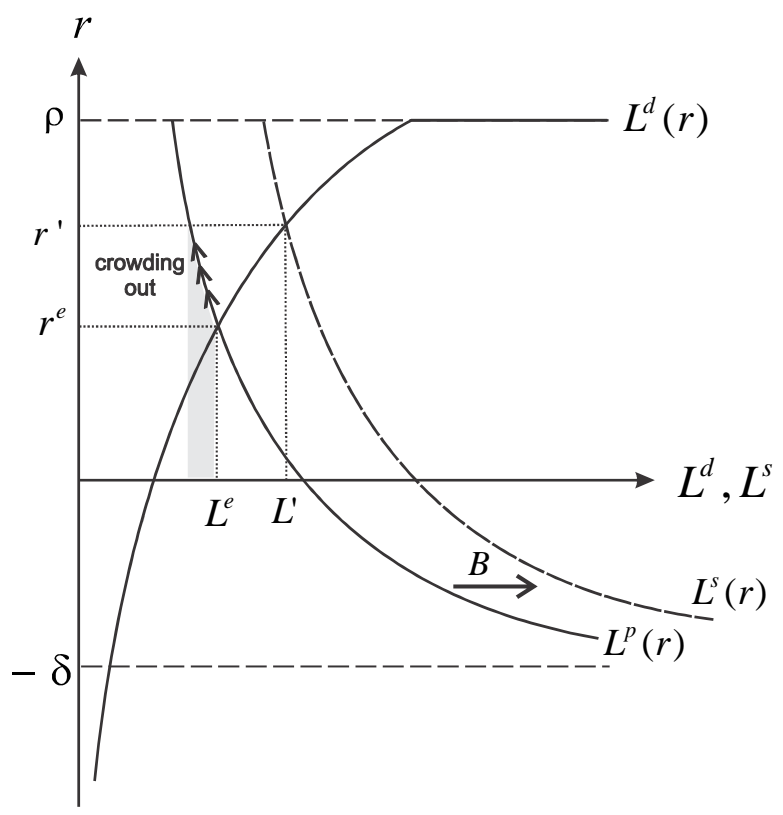

Figure 4: Public liquidity crowds out private liquidity

Finally, let us consider an increase in the public supply of liquidity. Differentiating (29) and (30) we obtain $d \theta / d B<0$ and $d r / d B>0$. As shown in Figure 4 , as $B$ increases, the curve

\footnotetext{
${ }^{21}$ For instance, with probability $\sigma^{u}$ an OTC-trader is in a match where there is some enforcement (e.g., due to reputation) and loans do not need to be secured with assets, and with probability $\sigma^{s}$ the trader is in a match with no enforcement in which case loans need to be secured. A regulation that requires OTC trades to be collateralized would correspond to an increase in $\sigma^{s}$ and a reduction in $\sigma^{u}$ so that $\sigma^{s}+\sigma^{u}$ remains unchanged.
} 
$L^{s}$ moves to the right and thus, the real interest rate increases. The higher interest rate makes firms less valuable and drives some of them out of the market (the private supply of liquidity declines as indicated by the arrows along the curve $L^{p}$ in Figure 4), market tightness decreases, and unemployment increases. Importantly, note that public liquidity crowds out private liquidity. ${ }^{22}$ However, the crowding out is not total so that aggregate liquidity increases and the services traded in the OTC market, $y$, increase as well:

$$
\frac{d y}{d B}=\frac{d\left(L^{p}+B\right)}{d B}=\left\{\sigma f^{\prime \prime}(y) \gamma^{2} \frac{\delta+p(\theta)[1-\eta(\theta)]}{(\varphi-w) q^{\prime}(\theta)[\delta+p(\theta)]^{2}}+1\right\}^{-1} \in(0,1) .
$$

These comparative statics suggest the existence of a trade-off for the policymaker between the net output of the OTC sector and the rate of unemployment. We will study the welfare implications of this trade-off in Section 5.

\section{Dynamics of the labor market under scarce liquidity}

We now turn to the transitional dynamics of the model. We will ask whether the dynamics of unemployment are affected if liquidity is scarce. Out of steady state the value of a filled job solves the following flow Bellman equation:

$$
r V_{F}=\varphi-w-\delta V_{F}+\dot{V}_{F}
$$

The novelty relative to (1) is the last term on the right side that takes into account the change in the value of the firm over time. The law of motion for employment is

$$
\dot{n}=p(\theta)(1-n)-\delta n
$$

According to (34) the change in employment is equal to the flow of job creations - the number of unemployed, $1-n$, times the job finding rate, $p(\theta)$ - net of the flow of job destructions - the number of jobs, $n$, times the separation rate, $\delta$.

In order to transform (33)-(34) into a system of autonomous differential equations we use two optimality conditions. First, from the free-entry condition that must hold at any point in time, $\gamma / q(\theta)=V_{F}$, there is a one-to-one positive relationship between the value of a firm and market tightness, i.e., $\theta=\theta^{e}\left(V_{F}\right)$ with $\theta^{e l}>0, \theta^{e}(0)=0$, and $\theta^{e}(+\infty)=+\infty$. Similarly, we define the job finding rate as a function of the value of a firm, $p^{e}\left(V_{F}\right)=p\left[\theta^{e}\left(V_{F}\right)\right]$, with $p^{e l}>0, p^{e}(0)=0$, and $p^{e}(+\infty)=+\infty$.

Second, from (22) and the market-clearing condition, $a(t)=B+n(t) V_{F}(t)$, the real interest rate is $r(t)=\rho+\sigma\left\{1-f^{\prime}[y(t)]\right\}$ with $y(t)=\min \left\{y^{*}, B+n(t) V_{F}(t)\right\}$. So there is a one-to-one

\footnotetext{
${ }^{22}$ Similarly, in Lagos and Rocheteau (2008) a decrease in the money growth rate increases aggregate real balances (public liquidity) which reduces capital accumulation (private liquidity). See also Williamson (2012) for an environment where an increase in public liquidity crowds private liquidity out.
} 


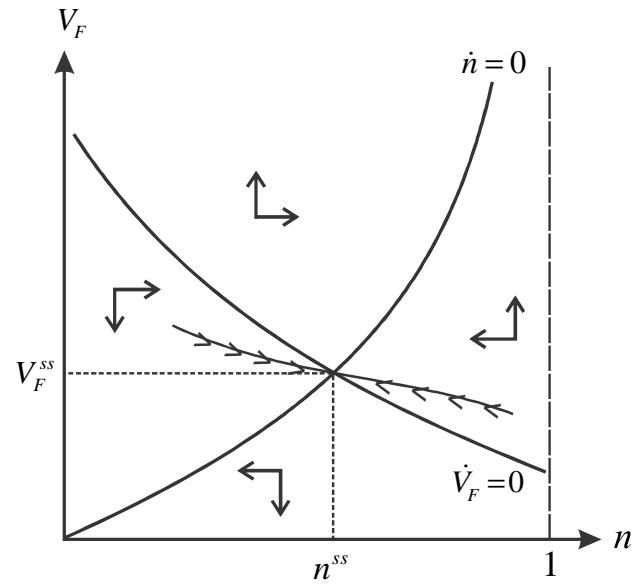

Scarce liquidity

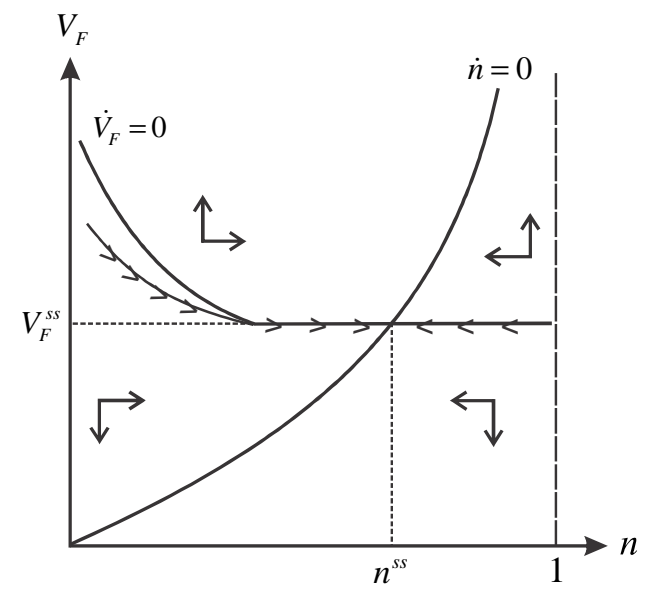

Abundant liquidity

Figure 5: Phase diagram

positive relationship between the real interest rate and the liquidity supply, $r=r^{e}\left(B+n V_{F}\right)$ with $r^{e}(0)=-\infty$ and $r^{e l}>0$ if $B+n V_{F}<y^{*}$, and $r^{e}\left(B+n V_{F}\right)=\rho$ otherwise.

From these two observations we rewrite (33)-(34) as the following system of differential equations:

$$
\begin{aligned}
\dot{V}_{F} & =\left[r^{e}\left(B+n V_{F}\right)+\delta\right] V_{F}+w-\varphi \\
\dot{n} & =p^{e}\left(V_{F}\right)(1-n)-\delta n .
\end{aligned}
$$

Figure 5 depicts the phase diagram of the system (35)-(36). From (35) the equation of the $V_{F^{-}}$ isocline, $\dot{V}_{F}=0$, is $V_{F}=(\varphi-w) /\left[r^{e}\left(B+n V_{F}\right)+\delta\right]$. It is downward sloping since as $n$ increases the real interest rate increases, which reduces the value of firms. It has a vertical asymptote at $n=0$ if $r^{e}(B) \leq-\delta$, i.e., $B \leq f^{\prime-1}[1+(\rho+\delta) / \sigma]$. Moreover, for all $n \geq\left(y^{*}-B\right)(\rho+\delta) /(\varphi-w)$, the $V_{F}$-isocline is horizontal at $V_{F}=(\varphi-w) /(\rho+\delta)$.

The equation of the $n$-isocline, $\dot{n}=0$, is given by $n=p^{e}\left(V_{F}\right) /\left[\delta+p^{e}\left(V_{F}\right)\right]$. It is upward sloping since a higher value of jobs is associated with a higher job finding rate, and hence a higher level of employment. Moreover, it goes through the origin, and it has a vertical asymptote at $n=1$. The intersection of the two isoclines defines the unique steady state, $\left(n^{s s}, V_{F}^{s s}\right)$.

Linearizing around the steady state the system (35)-(36) can be rewritten as:

$$
\left(\begin{array}{c}
\dot{V}_{F} \\
\dot{n}
\end{array}\right)=\left(\begin{array}{cc}
+ & + \\
+ & -
\end{array}\right)\left(\begin{array}{c}
V_{F}-V_{F}^{s s} \\
n-n^{s s}
\end{array}\right)
$$

The determinant of the Jacobian matrix is negative implying that the steady state is a saddle point. Hence, starting from any initial condition, $n_{0}$, there is a unique equilibrium given by the saddle 
path of the system represented graphically in Figure 5 by a downward sloping curve with arrows pointing toward the steady state.

Consider a situation of scarce liquidity, $B+n^{s s} V_{F}^{s s}<y^{*}$, as represented in the left panel of Figure 5. If the initial level of employment is lower than its steady-state value, then the value of a filled job and market tightness are greater than their steady-state values, and they decline over time as the economy converges to its steady state along the saddle path. From (33) $\dot{V}_{F}<0$ implies $V_{F}(t)<(\varphi-w) /[r(t)+\delta]$ for all $t$. Moreover, $V_{F}^{s s}=(\varphi-w) /\left(r^{s s}+\delta\right)<V_{F}(t)$. Consequently, $r(t)<r^{s s}$. The interest rate along the transition path is smaller than its steady-state value.

If liquidity is abundant, $B+n^{s s} V_{F}^{s s} \geq y^{*}$, then $r^{e}\left(B+n^{s s} V_{F}^{s s}\right)=\rho$. As shown in the right panel of Figure 5 the saddle path in the neighborhood of the steady state is such that $V_{F}=(\varphi-w) /(\rho+\delta)$ is constant, as in the standard MP model. If the initial value for employment is sufficiently low, $n(0)<\underline{n} \equiv(\rho+\delta)\left(y^{*}-B\right) /(\varphi-w)$, the saddle path is downward sloping. Along the equilibrium path the value of jobs decreases until the level of employment reaches a certain threshold, $\underline{n}$. Once this threshold is reached, the value of jobs and the interest rate remain constant while employment keeps on increasing until it reaches its steady-state value.

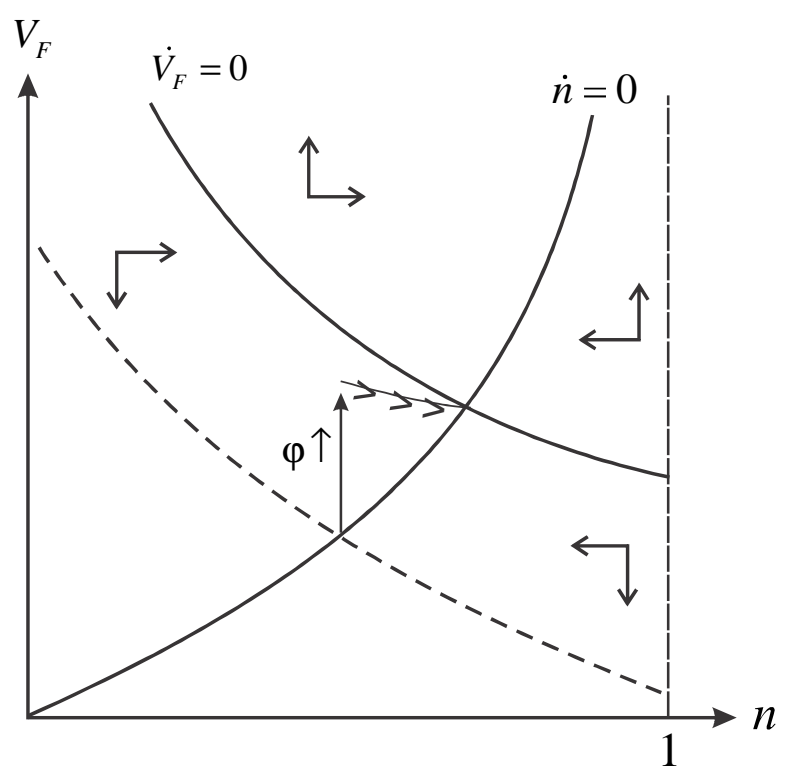

Figure 6: Dynamics following a productivity shock

Next, we show how scarce liquidity affects the path of labor market variables under different shocks. We first describe a positive, unanticipated, productivity shock that raises $\varphi{ }^{23}$ The economy starts at a steady state where liquidity is scarce, $y<y^{*}$. In Figure 6 the economy is at the

\footnotetext{
${ }^{23}$ The shock is sectoral in the sense that the productivity, $f$, in the OTC sector is unaffected. If the productivity in the OTC sector was increased as well, then the demand for liquidity would be higher and the overall effect on the interest rate would be ambiguous.
} 
intersection of the dashed $V_{F}$-isocline and the $n$-isocline. An increase in $\varphi$ shifts the $V_{F}$-isocline upward. The value of a firm jumps instantly upward to bring the economy to its new saddle path. Because the saddle path is downward sloping the value of firms and market tightness overshoot their new steady-state value. This overshooting happens because agents anticipate that interest rates will increase over time as the creation of new firms will raise the supply of private liquidity. As a result firms maximize their profits by opening more vacancies early on following the productivity shock.

Consider next an increase in the public supply of liquidity, $B$. The $V_{F}$-isocline moves downward. The value of filled jobs and market tightness fall below their new steady-state value because agents anticipate that the increase in public liquidity will crowd private liquidity out gradually over time. As the private liquidity declines, the real interest rate decreases making it optimal for firms to postpone the opening of some vacancies.

So far we have kept the public supply of liquidity constant over time. Alternatively, the path for the public supply of liquidity could be chosen so as to keep the real interest rate constant. In that case the steady state associated with (35)-(36) is a saddle point and the saddle path is an horizontal line, as in the right panel in Figure 5. This means that along the transitional path the value of jobs and market tightness are constant, and only the level of employment changes over time. From (36) the path for employment is

$$
n(t)=\frac{p(\theta)}{\delta+p(\theta)}+\left[n(0)-\frac{p(\theta)}{\delta+p(\theta)}\right] e^{-[\delta+p(\theta)] t},
$$

where $p(\theta) /[\delta+p(\theta)]$ is the steady-state employment rate.

\section{The liquidity-unemployment trade-off}

We saw in Sections 3 and 4 that there exists a trade-off between the provision of liquidity to the OTC sector and the interest rate faced by firms - and hence unemployment. On the one hand an increase in public liquidity benefits the OTC sector by providing more collateral. It follows that

$y$ increases and traders' total surplus increases as well. On the other hand an increase in public liquidity raises the interest rate and reduces job creation. In the following we explore the normative implications of this trade-off.

We measure social welfare by the discounted sum of the utility flows of all agents (OTC-traders, workers, and firms) in the economy, i.e.,

$$
\mathcal{W}=\int_{0}^{+\infty} e^{-\rho t}\{\sigma\{f[y(t)]-y(t)\}+n(t) \varphi-\theta(t)[1-n(t)] \gamma\} d t
$$

According to (38) a measure $\sigma=\alpha / 2$ of matches are formed in the OTC market, and in each match the net output is $f(y)-y$. In the labor market there is a measure, $n$, of filled jobs, where each job 
produces $\varphi$ units of output. Finally, each of the $\theta(1-n)=v$ vacancies incurs a flow cost $\gamma^{24}$

The constrained-efficient allocation maximizes $\mathcal{W}$ with respect to $\{y(t), v(t), n(t)\}$ subject to the law of motion for employment, $\dot{n}=h(1-n, v)-\delta n$. Given that $\mathcal{W}$ is additively separable in terms of the surpluses of the OTC-traders and the net output of the labor market, the solution to the planner's problem is such that $y(t)=y^{*}\left(\right.$ where $\left.f^{\prime}\left(y^{*}\right)=1\right)$ for all $t$. Moreover, from the Maximum Principle $\theta=\theta^{*}$, where $\theta^{*}$ solves

$$
(\rho+\delta) \frac{\gamma}{q\left(\theta^{*}\right)}=\eta\left(\theta^{*}\right) \varphi-\left[1-\eta\left(\theta^{*}\right)\right] \gamma \theta^{*}
$$

where $\eta(\theta) \equiv \theta p^{\prime}(\theta) / p(\theta)$ is the elasticity of the matching function.

Next we determine the conditions under which the equilibrium allocation coincides with the constrained-efficient one. From (22) $y(t)=y^{*}$ in equilibrium if and only if $r(t)=\rho$ for all $t .{ }^{25}$ This condition holds if and only if liquidity is abundant, $B+L^{p}(\rho) \geq y^{*}$. The comparison from (3) and (39) shows that $\theta(t)=\theta^{*}$ if and only if $w=w^{*}$ where

$$
w^{*}=\left[1-\eta\left(\theta^{*}\right)\right]\left(\varphi+\theta^{*} \gamma\right)
$$

The requirement $w=w^{*}$ corresponds to the Hosios (1990) condition for efficiency in markets with search externalities. If $w>w^{*}$, then market tightness is too low and unemployment too high relative to the constrained-efficient benchmark. This inefficiency arises because of a congestion externality according to which firms do not internalize the effect of their entry decisions on other firms' vacancy filling rate. ${ }^{26}$

Next, we show that a policy that keeps liquidity scarce when the unemployment rate is inefficiently high can lower the interest rate and raise welfare. In order to establish this result we focus on equilibria where the supply of liquidity, $L^{p}+B$, is constant across time. This means that the policymaker adjusts the public liquidity in order to compensate for any change in private liquidity, $\dot{B}=-\dot{L}^{p}$. As a result the real interest rate, $r$, the services traded in OTC matches, $y$, and market tightness, $\theta$, are also constant. Substituting $n(t)$ by its expression given by (37) into the expression

\footnotetext{
${ }^{24}$ Provided that we allow for lump-sum transfers/subsidies across agents, any Pareto-optimal allocation will maximize $\mathcal{W}$ subject to the constraints imposed by the matching technology.

${ }^{25}$ Whether or not the constrained-efficient allocation is implementable depends crucially on the choice of the trading mechanism in the OTC market. If the terms of trade in the OTC matches are determined according to the Nash solution, then the constrained-efficient allocation is not achievable since at $r=\rho$ the output is inefficiently low, $y<y^{*}$. See, e.g., Lagos and Wright (2005) and Rocheteau and Wright (2005) in a model with free entry of sellers. In contrast, if following $\mathrm{Hu}$, Kennan, and Wallace (2009) the trading mechanism in the OTC market is chosen optimally among all pairwise Pareto-efficient and individually rational trading mechanisms, then the constrainedefficient allocation is implementable for all $r>\bar{r}$ where $\bar{r}$ is a threshold less than $\rho$. See Rocheteau (2012) in the context of a monetary model with endogenous participation.

${ }^{26}$ This finding is related to the result according to which in monetary economies with search frictions, social efficiency requires both the Friedman rule and the Hosios condition to hold. See Cooley and Quadrini (2004) and Berentsen, Rocheteau, and Shi (2007). In our context, the Friedman rule corresponds to $r=\rho$, i.e., liquidity is not costly to hold.
} 
for social welfare, (38), we obtain:

$$
\mathcal{W}=\overbrace{\frac{\sigma[f(y)-y]}{\rho}}^{\text {OTC-sector }}+\overbrace{\frac{\varphi}{\rho}-\frac{\rho[1-n(0)]+\delta}{[\rho+\delta+p(\theta)] \rho}(\varphi+\theta \gamma)}^{\text {Labor market }} .
$$

The first term on the right side of (41) is the discounted sum of OTC-traders' surpluses. The second and third terms correspond to the net output in the labor market. From (41) a change in the interest rate has the following effect on welfare:

$$
\frac{d \mathcal{W}}{d r}=\overbrace{\frac{\sigma\left[f^{\prime}(y)-1\right]}{\rho} \frac{\partial y}{\partial r}}^{\text {OTC-sector }}+\overbrace{\frac{\partial \mathcal{W}}{\partial \theta} \frac{\partial \theta}{\partial r}}^{\text {Labor market }},
$$

where

$$
\frac{\partial \mathcal{W}}{\partial \theta}=-q(\theta)\left\{\frac{[1-n(0)]+\delta / \rho}{[\rho+\delta+p(\theta)]^{2}}\right\}\left\{\frac{\gamma}{q(\theta)}(\rho+\delta)-\varphi \eta(\theta)+\theta \gamma[1-\eta(\theta)]\right\} .
$$

The first term on the right side of (42) is the effect of a change in the interest rate on the total surplus of the OTC sector. An increase in the interest reduces the cost of holding liquidity, which from (22) induces OTC-traders to hold more liquid assets and to trade larger quantities. The second term on the right side of (42) is the effect of a change in the interest rate on the labor market. From the discussion above the overall effect on welfare depends on whether the wage is larger or smaller than $w^{*}$.

Suppose that $r$ is close to $\rho$, i.e., liquidity is close to being abundant. From (22) $y$ is close to $y^{*}$ so that the first term on the right side of (42) is close to 0, i.e.,

$$
\left.\frac{d \mathcal{W}}{d r}\right|_{r \approx \rho}=\frac{\partial \mathcal{W}}{\partial \theta} \frac{\partial \theta}{\partial r}
$$

It follows from (43) that if $w>w^{*}, d \mathcal{W} /\left.d r\right|_{r \approx \rho}<0$, i.e., it is optimal to keep liquidity scarce so as to reduce the interest rate below the rate of time preference. By reducing the interest rate the policymaker raises the inefficiently low market tightness and reduces the inefficiently high unemployment. It also reduces OTC-traders' surpluses by making liquidity more costly. Provided that the decrease in the interest rate is not too large, the welfare gain for the labor market outweighs the welfare loss for the OTC sector.

\section{Public liquidity management}

Our benchmark model predicts that a more abundant public liquidity drives the real interest up. In order to show that this result is consistent with the common view of a liquidity channel of openmarket operations, we provide a more realistic description of monetary policy by extending our model to allow for two types of public liquidity: fiat money and nominal bonds. Fiat money is an 
intrinsically useless asset that pays no dividend, and nominal bonds are pure discount bonds that yield one unit of fiat money at a Poisson rate equal to one. The supply of fiat money, $\mathcal{M}(t)$, and the supply of nominal bonds, $\mathcal{B}(t)$, grow at a constant rate, $\pi$. Consequently, the ratio $\mathcal{B}(t) / \mathcal{M}(t) \in \mathbb{R}$ is constant over time. The government's budget constraint is

$$
v^{m} \mathcal{B}=\Upsilon+g_{\mathcal{M}} \mathcal{M} v^{m}+g_{\mathcal{B}} \mathcal{B} v^{b}
$$

where $g_{\mathcal{B}}$ and $g_{\mathcal{M}}$ denote the rates at which new bonds and money, respectively, are issued, $v^{m}$ denotes the real value of a unit of money in terms of the numéraire good, $v^{b}$ the real value of a nominal bond, and $\Upsilon$ is a lump-sum tax on OTC traders. According to (44) the government redeems bonds that mature, $v^{m} \mathcal{B}$, by raising lump-sum taxes, $\Upsilon$, issuing money, $g_{\mathcal{M}} \mathcal{M} v^{m}$, and new bonds, $g_{\mathcal{B}} \mathcal{B} v^{b} .^{27}$

We also extend our model to introduce liquidity differences across assets. Indeed, public liabilities are considered more safe and liquid than private ones - treasuries are universally accepted as collateral whereas corporate debt or equity can be used as collateral in repo markets but are not acceptable in some derivatives markets. ${ }^{28}$ Among public liabilities, fiat money is universally accepted while government bonds do not serve as means of payment in retail transactions but have a role as collateral in financial trades.

In order to generate liquidity differences between money, government bonds, and private claims we assume that fiat money is acceptable as means of payment in all matches while nominal bonds and private assets are eligible as collateral in a fraction of OTC matches. Formally, there is a fraction $\mu^{m}$ of matches where only fiat money is acceptable, and a fraction $\mu^{g}$ of matches where only public liquidity - i.e., fiat money and government bonds - can be used as a media of exchange. In the remaining fraction of matches, $\mu^{p}=1-\mu^{m}-\mu^{g}$, all assets are acceptable. ${ }^{29}$ See Figure 7 for a graphical representation of assets' acceptability in OTC matches.

We denote by $m$ the real money holdings of an OTC-trader, by $g$ his holdings of government bonds, and by $a$ his holdings of private assets (in terms of the numéraire). The rate of return of

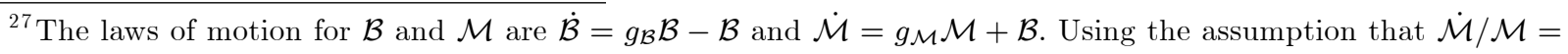
$\dot{\mathcal{B}} / \mathcal{B}=\pi$ these two equations can be rearranged as $g_{\mathcal{B}}=1+\pi$ and $g_{\mathcal{M}}=\pi-\mathcal{B} / \mathcal{M}$. So given $\pi$ and $\mathcal{B} / \mathcal{M}$ the rates of bonds and money creation are uniquely determined.

${ }^{28}$ See the ISDA (1996, Chapter 2, Section 3) for criteria for collateral eligibility in derivatives transactions. Considerations for eligibility include liquidity, volatility, collateral quality (credit rating), and time remaining to maturity, among many other factors. Also, the Federal Reserve accepts a narrow range of securities as collateral while other central banks (e.g., Bank of Japan) accept a wider set of securities. See Table 3 in BIS (2001). Private fixed income securities are less liquid than public ones because private issues tend to be smaller and more heterogeneous than those of the government, and they are more difficult to value and to hedge than government securities (BIS, 2001).

${ }^{29}$ One can endogenize the $\mu$ 's by introducing a costly technology to authenticate assets (see, e.g., Kim, 1996 and Lester, Postlewaite, and Wright, 2012), an informational asymmetry regarding the terminal value of the asset through an adverse selection problem (e.g., Guerrieri, Shimer, and Wright, 2010; Rocheteau, 2011; Guerrieri and Shimer, 2012; Chang, 2012) or a moral hazard problem (e.g., Li, Rocheteau, and Weill, 2012). The liquidity differences across assets can also be generated by the trading mechanism in pairwise meetings as in Zhu and Wallace (2007) and Nosal and Rocheteau (2013). Finally, one can think of the $\mu$ 's as capturing institutional restrictions on the eligibility of securities as collateral, such as central bank collateral practices.
} 


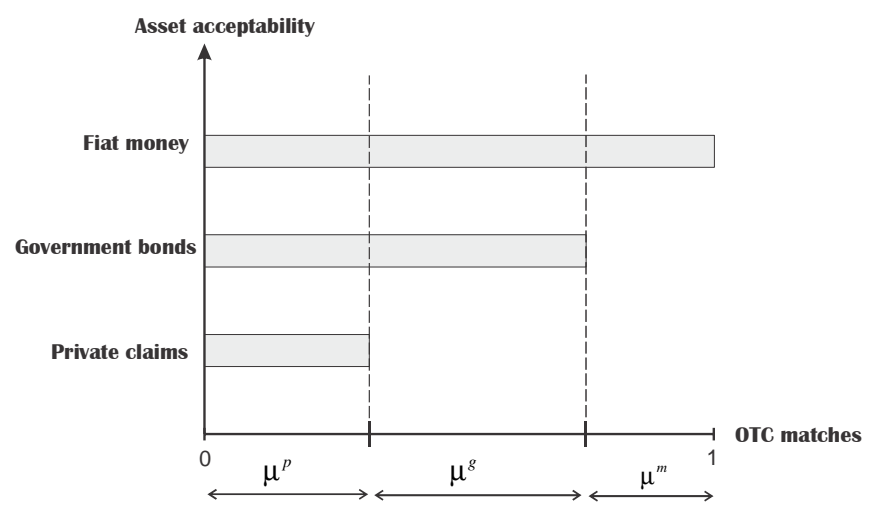

Figure 7: Assets' acceptability in OTC matches

fiat money is $r^{m}$, the rate of return of bonds is $r^{g}$, and the rate of return of private assets is $r$. The problem of the OTC-trader with an initial portfolio $\left(m_{0}, g_{0}, a_{0}\right)$ is

$$
\begin{aligned}
W\left(m_{0}, g_{0}, a_{0}\right) & =\max _{m(t), \varepsilon^{m}(t), \varepsilon^{g}(t), a(t), c(t)}\left\{\mathbb{E} \int_{0}^{T_{1}} e^{-\rho t} c(t) d t+e^{-\rho T_{1}} Z\left[m\left(T_{1}\right), g\left(T_{1}\right), a\left(T_{1}\right)\right]\right\} \\
\text { s.t. } \quad \dot{a} & =r^{m} m+r^{g} g+r a-\varepsilon^{m}-\varepsilon^{g}-c-\Upsilon \\
\dot{m} & =\varepsilon^{m} \\
\dot{g} & =\varepsilon^{g} \\
{[m(0), g(0), a(0)] } & =\left(m_{0}, g_{0}, a_{0}\right)
\end{aligned}
$$

where $Z(m, g, a)$ is the continuation value of an OTC-trader upon being matched. The main difference with respect to our benchmark model is the fact that the trader's portfolio is now composed of assets with different liquidity properties and rates of return. As a result, the continuation value of a trader, $Z(m, g, a)$, depends on the composition of his portfolio and not only on its total value. Adding (46), (47), and (48) the change in the trader's wealth, $\dot{a}+\dot{m}+\dot{g}$, is equal to the interest payments on his portfolio, $r^{m} m+r^{g} g+r a$, net of consumption, $c$, and taxes, $\Upsilon$.

The value function of a matched trader solves

$$
\begin{aligned}
Z(m, g, a)= & \frac{\mu^{p}}{2} \max _{y^{p} \leq m+g+a}\left\{f\left(y^{p}\right)-y^{p}\right\}+\frac{\mu^{g}}{2} \max _{y^{g} \leq m+g}\left\{f\left(y^{g}\right)-y^{g}\right\} \\
& +\frac{\mu^{m}}{2} \max _{y^{m} \leq m}\left\{f\left(y^{m}\right)-y^{m}\right\}+W(m, g, a) .
\end{aligned}
$$

With probability $1 / 2$ the trader is the buyer in the match, in which case he can make a take-it-orleave-it offer to the seller in order to maximize his surplus, $f(y)-y$. With probability $\mu^{p}$ all assets are acceptable and the trader can transfer up to $m+g+a$ in exchange for $y^{p}$. With probability $\mu^{g}$ fiat money and government bonds are acceptable so that the trader can transfer up to $m+g$ 
to purchase $y^{g}$. Finally, with probability $\mu^{m}$ only fiat money is acceptable and the trader can only transfer up to $m$ in exchange for $y^{m}$.

From the Maximum Principle, the OTC-trader's optimal portfolio solves

$$
\begin{aligned}
\frac{\rho-r}{\sigma} & =\mu^{p}\left[f^{\prime}\left(y^{p}\right)-1\right] \\
\frac{\rho-r^{g}}{\sigma} & =\mu^{p}\left[f^{\prime}\left(y^{p}\right)-1\right]+\mu^{g}\left[f^{\prime}\left(y^{g}\right)-1\right] \\
\frac{\rho-r^{m}}{\sigma} & =\mu^{p}\left[f^{\prime}\left(y^{p}\right)-1\right]+\mu^{g}\left[f^{\prime}\left(y^{g}\right)-1\right]+\mu^{m}\left[f^{\prime}\left(y^{m}\right)-1\right] .
\end{aligned}
$$

The novelty relative to the previous section is that the demand for an asset depends on the eligibility of that asset in OTC transactions. Equation (51) defines the optimal choice of private assets. The left side of (51) is the holding cost of private assets as measured by the difference between the rate of time preference and the rate of return of the asset, $\rho-r$, multiplied by the expected time before the trader receives an opportunity to purchase OTC services, $1 / \sigma$. The right side of (51) indicates the expected marginal surplus from holding an additional unit of private assets. Those assets can only be used in a fraction $\mu^{p}$ of all matches, in which case the marginal surplus of the trader is $f^{\prime}\left(y^{p}\right)-1$. Equations (52) and (53) have a similar interpretation. Substracting (51) from (52) and (52) from (53) the rate-of-return differences across assets are

$$
\begin{aligned}
r-r^{g} & =\mu^{g} \sigma\left[f^{\prime}\left(y^{g}\right)-1\right] \geq 0 \\
r^{g}-r^{m} & =\mu^{m} \sigma\left[f^{\prime}\left(y^{m}\right)-1\right] \geq 0 .
\end{aligned}
$$

Private assets dominate government bonds in their rate of return provided that $\mu^{g}>0$ and $y^{g}<y^{*}$. Similarly, government bonds dominate fiat money in their rate of return if $\mu^{m}>0$ and $y^{m}<y^{*}$.

We focus on steady-state equilibria where the real supply of money, $M \equiv v^{m} \mathcal{M}$, and the real supply of bonds, $B \equiv v^{b} \mathcal{B}$, are constant over time. It follows that $\dot{v}^{m} / v^{m}=\dot{v}^{b} / v^{b}=-\pi$. Since fiat money yields no dividend its rate of return is

$$
r^{m}=\dot{v}^{m} / v^{m}=-\pi
$$

The price of bonds solves the following asset pricing condition,

$$
r^{g} v^{b}=v^{m}-v^{b}+\dot{v}^{b}
$$

According to (57) a nominal bond matures at Poisson rate equal to one, in which case the bond holder enjoys a capital gain equal to $v^{m}-v^{b}$. The last term on the right side of (57) is the change in the value of bonds over time. From (57) the nominal interest rate on government bonds is

$$
i^{g}=r^{g}+\pi=\frac{v^{m}}{v^{b}}-1
$$


Notice that $v^{b} / v^{m}$ is the nominal price of a newly-issued bond, and hence $1 /\left(v^{b} / v^{m}\right)$ is the gross nominal interest rate.

From the buyer-takes-all bargaining procedure, the quantity traded in an OTC match is the minimum between the real value of the buyer's acceptable assets in that match and the socially efficient quantity. By market clearing this gives:

$$
\begin{aligned}
y^{m} & =\min \left\{M, y^{*}\right\} \\
y^{g} & =\min \left\{v^{m} \mathcal{M}+v^{b} \mathcal{B}, y^{*}\right\}=\min \left\{M\left(1+\frac{\mathcal{B}}{\left(1+i^{g}\right) \mathcal{M}}\right), y^{*}\right\} \\
y^{p} & =\min \left\{v^{m} \mathcal{M}+v^{b} \mathcal{B}+L^{p}, y^{*}\right\}=\min \left\{M\left(1+\frac{\mathcal{B}}{\left(1+i^{g}\right) \mathcal{M}}\right)+L^{p}, y^{*}\right\} .
\end{aligned}
$$

Definition 2 A steady-state equilibrium is a list, $\left(y^{m}, y^{g}, y^{p}, r^{m}, r^{g}, r, i^{g}, M, \theta\right)$, that solves (3), (51)-(53), (56), (58), and (59)-(61). An equilibrium is monetary if $M>0$.

In the following we study two special cases: (i) government bonds and private assets are equally liquid; (ii) money and government bonds are perfect substitutes. We will use these two cases to discuss how monetary policies (open-market operations and changes in the money growth rate) and shocks to the eligibility of private assets affect interest rates and unemployment.

\section{Monetary policy}

We assume first that public bonds and private assets are perfect substitutes by setting $\mu^{g}=0 .{ }^{30}$ Hence, in a fraction $\mu^{p}$ of matches all assets are eligible as collateral while in the remaining fraction of matches, $\mu^{m}=1-\mu^{p}$, only fiat money can serve as medium of exchange. From (54) $\mu^{g}=0$ implies $r=r^{g}$, so that bonds and private claims have the same rate of return.

We reduce an equilibrium to a nominal interest rate, $i^{g}$, and aggregate real balances, $M$. From (55), (58), and (59), the nominal interest rate is

$$
i^{g}=\sigma \mu^{m}\left[f^{\prime}(M)-1\right]^{+}
$$

where $[x]^{+}=\max \{x, 0\}$. This negative relationship between $i^{g}$ and $M$ is represented by the curve labeled LPM (Liquidity Premium Money) in Figure 8. Intuitively, as real balances increase, the liquidity premium on fiat money as measured by the nominal interest rate, $i^{g}$, decreases. From (51), (58), and (61) we obtain a second condition,

$$
i^{g}=\rho+\pi-\sigma \mu^{p}\left\{f^{\prime}\left[M\left(1+\frac{\mathcal{B}}{\left(1+i^{g}\right) \mathcal{M}}\right)+L^{p}\left(i^{g}-\pi\right)\right]-1\right\}^{+} .
$$

\footnotetext{
${ }^{30}$ This case is similar to the one studied in Williamson (2012, section 6) where the fraction $\mu^{p}$ of matches are interpreted as monitored trades and the remain $1-\mu^{p}$ matches are interpreted as unmonitored trades. In addition Williamson (2012) allows agents to reallocate their portfolios after their type of meeting (monitored vs unmonitored) has been realized through a deposit contract arrangement.
} 
Equation (63) gives a positive relationship between $i^{g}$ and $M$ and is represented by the curve $L P B$ (Liquidity Premium Bonds) in Figure 8. As $M$ increases, the liquidity premium on bonds as measured by the rate-of-return difference between illiquid assets and bonds, $\rho+\pi-i^{g}$, decreases, i.e., $i^{g}$ increases. An equilibrium is then a pair, $\left(i^{g}, M\right)$, that solves (62)-(63). Graphically it is given by the intersection of $L P M$ and $L P B$ in Figure 8.

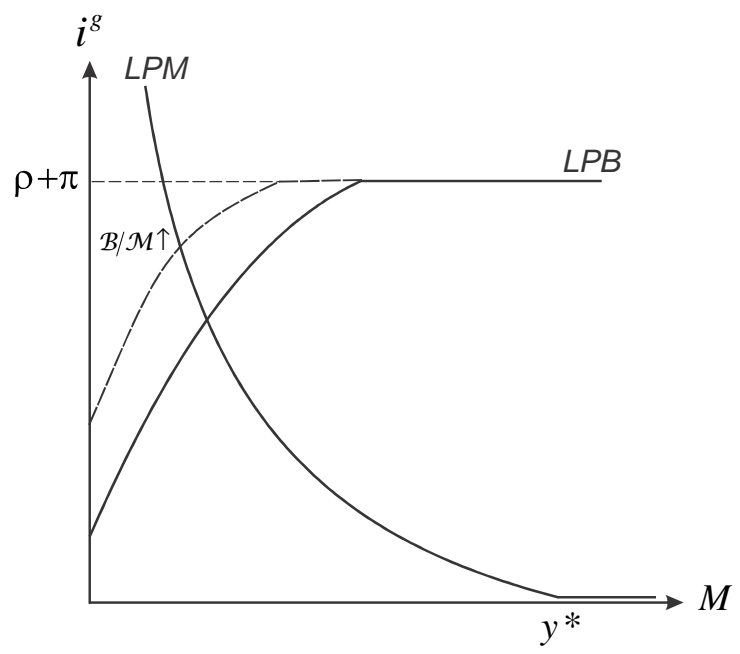

Figure 8: Real money balances and the nominal interest rate

Consider first equilibria where overall liquidity is abundant, $y^{p}=y^{*}$. In Figure 8 the $L P M$ curve intersects the $L P B$ curve in its horizontal part. From (63) $i^{g}=\rho+\pi$ and $r=\rho$. From (62) aggregate real balances are uniquely determined by

$$
\rho+\pi=\sigma \mu^{m}\left[f^{\prime}(M)-1\right]
$$

From (61) such an equilibrium exists if

$$
M\left[1+\frac{\mathcal{B}}{(1+\rho+\pi) \mathcal{M}}\right]+L^{p}(\rho) \geq y^{*}
$$

Suppose next that (64) does not hold, i.e., liquidity is scarce. In Figure 8 the $L P M$ curve intersects the $L P B$ curve in its upward-sloping part. If the ratio, $\mathcal{B} / \mathcal{M}$, increases, but the rate of growth of $\mathcal{B}$ and $\mathcal{M}$ is unchanged, then the $L P B$ curve moves to the left (as represented by the dashed line in Figure 8). As a result $i^{g}$ increases and $M$ decreases. The real interest rate, $r=i^{g}-\pi$, increases since there is more public liquidity to compete with private assets, which leads to a lower market tightness, a lower supply of private liquidity, and a higher unemployment.

Consider next a decrease in the rate of return of money, i.e., an increase in $\pi$. In Figure 8 the $L P B$ curve moves upward. So the nominal interest rate increases and aggregate real balances, $M$, 
decrease. In order to determine the effects on $r$, rewrite (63) as

$$
r=\rho-\sigma \mu^{p}\left\{f^{\prime}\left[M\left(1+\frac{\mathcal{B}}{(1+r+\pi) \mathcal{M}}\right)+L^{p}(r)\right]-1\right\}^{+} .
$$

As $\pi$ increases and $M$ declines, the right side of (65) decreases and hence, $r$ declines. This leads to an increase in market tightness and a reduction in unemployment, and hence, we obtain a long-run Phillips curve. Intuitively, inflation exacerbates the scarcity of liquidity in the economy by reducing the real value of public liquidity, which lowers the real interest rate and promotes the creation of private liquidity.

\section{Liquidity traps}

We consider next a class of equilibria, called "liquidity-trap" equilibria, where the nominal interest rate on government bonds is $i^{g}=0$. From (56) and (58) in such equilibria the real rates of return of money and government bonds are equalized, $r^{m}=r^{g}=-\pi$. From (55) a sufficient condition for such an outcome is $\mu^{m}=0$, i.e., money and bonds are acceptable in the same set of matches.

In order to study this special case we reduce an equilibrium to a pair composed of the real interest rate, $r$, and the real value of public liquidity, $M(1+\mathcal{B} / \mathcal{M})$. From $(51)$ the real value of public liquidity solves

$$
\frac{\rho-r}{\sigma}=\mu^{p}\left[f^{\prime}\left(y^{p}\right)-1\right]
$$

where $y^{p}=\min \left\{M(1+\mathcal{B} / \mathcal{M})+L^{p}, y^{*}\right\}$. Public liquidity, $M(1+\mathcal{B} / \mathcal{M})$ is a nondecreasing function of $r$, and it is strictly increasing if $\mu^{p}>0$ and $M(1+\mathcal{B} / \mathcal{M})<y^{*}-L^{p}(r)$. Intuitively, as $r$ increases private liquidity falls, and it is partially replaced with public liquidity.

The real interest is determined by (54),

$$
r+\pi=\mu^{g} \sigma\left[f^{\prime}\left(y^{g}\right)-1\right]
$$

where $y^{g}=\min \left\{M(1+\mathcal{B} / \mathcal{M}), y^{*}\right\}$. It is a nonincreasing function of $M(1+\mathcal{B} / \mathcal{M})$, and it is strictly decreasing if $\mu^{g}>0$ and $M(1+\mathcal{B} / \mathcal{M})<y^{*}$. Indeed, as public liquidity increases, the rate-of-return differential between public and private assets, $r+\pi$, decreases. The two equilibrium conditions, (66) and (67), determine uniquely $r$ and $M(1+\mathcal{B} / \mathcal{M})$.

The equilibrium is represented graphically in Figure 9 where (66) is labelled LPA (Liquidity Premium on private Assets) and (67) is labelled $L P G$ (Liquidity Premium on Government-supplied assets). We will focus on equilibria where $y^{p}<y^{*}$, i.e., the $L P G$ curve intersects the $L P A$ curve in its upward-sloping part. This requires the inflation rate not to be too close to $-\rho$ (the Friedman rule) since otherwise public liquidity, $M(1+\mathcal{B} / \mathcal{M})$, is close to $y^{*}$ and overall liquidity is abundant. ${ }^{31}$

\footnotetext{
${ }^{31}$ To see this, notice that $0 \leq r+\pi \leq \rho+\pi$. So if $\pi$ is sufficiently close to $-\rho$ it follows from (67) that $y^{g}=M(1+\mathcal{B} / \mathcal{M})$ is close to $y^{*}$ and $M(1+\mathcal{B} / \mathcal{M})+L^{p}>y^{*}$, i.e., $y^{p}=y^{*}$.
} 


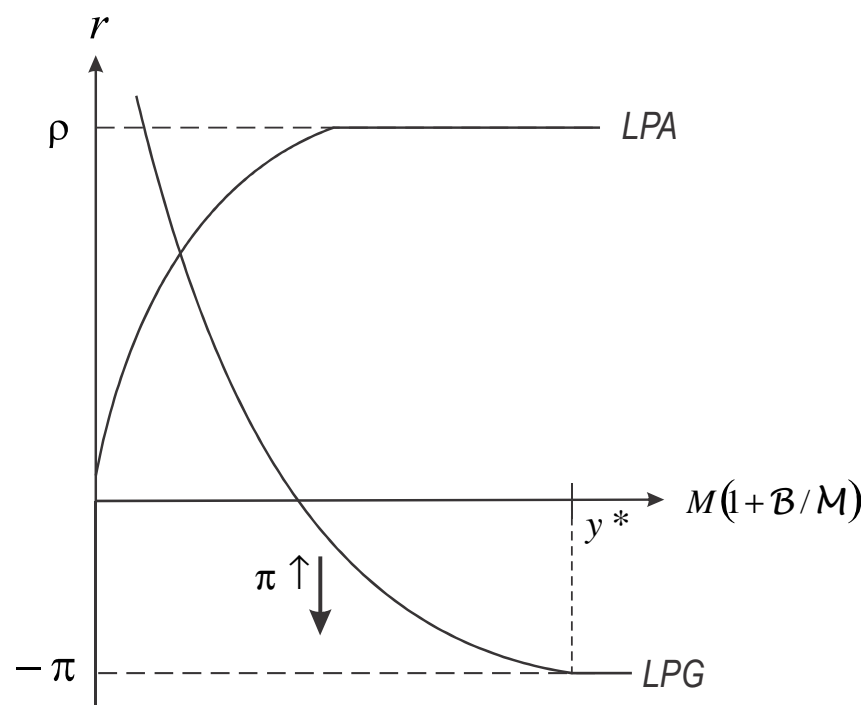

Figure 9: Liquidity-trap equilibrium

Let us consider first the effect of open-market operations. The real value of the public liquidity, $M(1+\mathcal{B} / \mathcal{M})$, is determined independently of $\mathcal{B}$ and $\mathcal{M}$. Consequently, a change in $\mathcal{B} / \mathcal{M}$ is neutral: it affects neither the real interest rate nor the quantities traded in the OTC market. The real value of money, $M$, adjusts so that the overall public liquidity remains unchanged. Hence, open-market operations are ineffective.

In contrast an increase in the inflation rate, $\pi$, provided the inflation rate is sufficiently high relative to the Friedman rule, reduces the real interest rate, which raises market tightness and reduces the unemployment rate. To see this, notice that the $L P G$ curve in Figure 9 moves downward as $\pi$ increases. Intuitively, an increase in $\pi$ corresponds to a decrease in the rate of return on public assets, $r^{m}=r^{g}=-\pi$. As a result, OTC traders reduce their holdings of public assets and increase their holdings of private assets. The price of private assets, $V_{F}$, increases which provides an incentive to open additional vacancies.

Consider next the case where $\mu^{m}>0$, fiat money is accepted in a larger set of matches than government bonds. From (55) the condition $i^{g}=0$ implies $y^{m}=y^{*}$. Consequently, the quantities traded in all matches are socially efficient, $y^{g}=y^{p}=y^{*}$, and all rates of return are equalized, $r=r^{g}=r^{m}=-\pi=\rho$. This is the Friedman rule outcome. As before a change in $\mathcal{B} / \mathcal{M}$ has no effect on the equilibrium allocations - open-market operations are irrelevant. Moreover, the inflation rate is pinned down by the rate of time preference. ${ }^{32}$

\footnotetext{
${ }^{32}$ As noticed by Wilson (1979) and Lagos (2010b), if one does not impose that $M$ is constant, the Friedman rule allocation can be implemented for any $\pi \in[-\rho, 0)$, in which case $M(1+\mathcal{B} / \mathcal{M}) \geq y^{*}$ is growing at rate $\rho+\pi<\rho$ (i.e., the transversality condition, $e^{-\rho t} M(t) \rightarrow 0$ as $t \rightarrow \infty$, holds).
} 


\section{Flights to liquidity}

We describe in the following a situation resembling a liquidity crisis. We consider a negative unanticipated liquidity shock that reduces the eligibility of private assets as collateral, i.e., $\mu^{p}$ falls. For instance, OTC-traders realize that there are severe informational asymmetries regarding the value of private assets, such as asset-backed securities. We investigate the implications of such a shock for the labor market and interest rates in the case where there is a single form of public liquidity, i.e., $\mu^{m}=0$, and $\mathcal{M}$ tends to 0 (with no loss in generality since fiat money and government bonds are perfect substitutes). From (55) $i^{g}=0$ and $v^{m}=v^{b}$. We take the real supply of bonds, $B$, as exogenous and we let $r^{g}$ be the endogenous variable. ${ }^{33}$ The real interest on private claims, $r$, is determined as in Figure 9 where the $L P G$ curve is replaced with a vertical line indicating the supply of public liquidity.

Suppose first that public liquidity is abundant, $B \geq y^{*}$. From (60)-(61) $y^{p}=y^{g}=y^{*}$, i.e., OTCtraders exchange the efficient quantities in all matches irrespective of private assets' eligibility as collateral. From (51)-(52) $r=r^{g}=\rho$. All assets have the same rate of return equal to the rate of time preference, i.e., there are no liquidity premia. Market tightness is equal to $\hat{\theta}$ as defined in (28). In this case a small change in $\mu^{p}$ has no effect on the equilibrium.

Suppose next that public liquidity is scarce, $B<y^{*}$, but overall liquidity is abundant, $B+L^{p} \geq$ $y^{*}$. From (60)-(61) $y^{g}<y^{p}=y^{*}$ and from (51)-(52) $r^{g}<r=\rho$. It follows that $\theta=\hat{\theta}$ and $L^{p}=$ $\gamma \hat{\theta} /[\delta+p(\hat{\theta})]$, i.e., the unemployment rate and the supply of private liquidity are at the levels that prevail in an economy with abundant liquidity. A decline in the acceptability of private assets, $\mu^{p}$, has no effect on the interest rate on private assets, $r$, market tightness, $\theta$, and unemployment, $u$, but it reduces the net output of the OTC market and it raises the rate-of-return differential between private and public liquidity, $r-r^{g}$.

We now analyze the case where liquidity is scarce in all meetings in the OTC market, $B+$ $L^{p}(\rho)<y^{*}$, which implies $r^{g}<r<\rho$. From (51) the marginal benefit from holding private assets, $\mu^{p}\left[f^{\prime}\left(y^{p}\right)-1\right]$, and the demand for private liquidity fall. In Figure 10 the curve $L^{d}(r)=$ $f^{\prime-1}\left[1+(\rho-r) / \sigma \mu^{p}\right]$ moves to the left and the steady-state equilibrium switches from " 0 " to " 1 ". The interest rate on private assets increases and aggregate liquidity shrinks. From (54) the rate-ofreturn differential between private and public liquidity increases, which is consistent with a flight to liquidity/safety according to which OTC-traders want to reallocate their portfolios toward the most liquid assets. ${ }^{34}$ The higher interest rate on private claims reduces incentives to open jobs and raises unemployment.

\footnotetext{
${ }^{33}$ From Footnote 27 if $\mathcal{B} / \mathcal{M} \rightarrow \infty$, then $g_{\mathcal{M}} \rightarrow-\infty$. As soon as nominal bonds mature, the units of fiat money they yield are withdrawn so that there is no fiat money in the economy.

${ }^{34}$ During the subprime crisis, the flight-to-quality was confined to AAA-rated bonds, and the illiquidity component of the rate of return of bonds with lower grades rose sharply (Dick-Nielsen, Feldhütter, and Lando, 2012).
} 


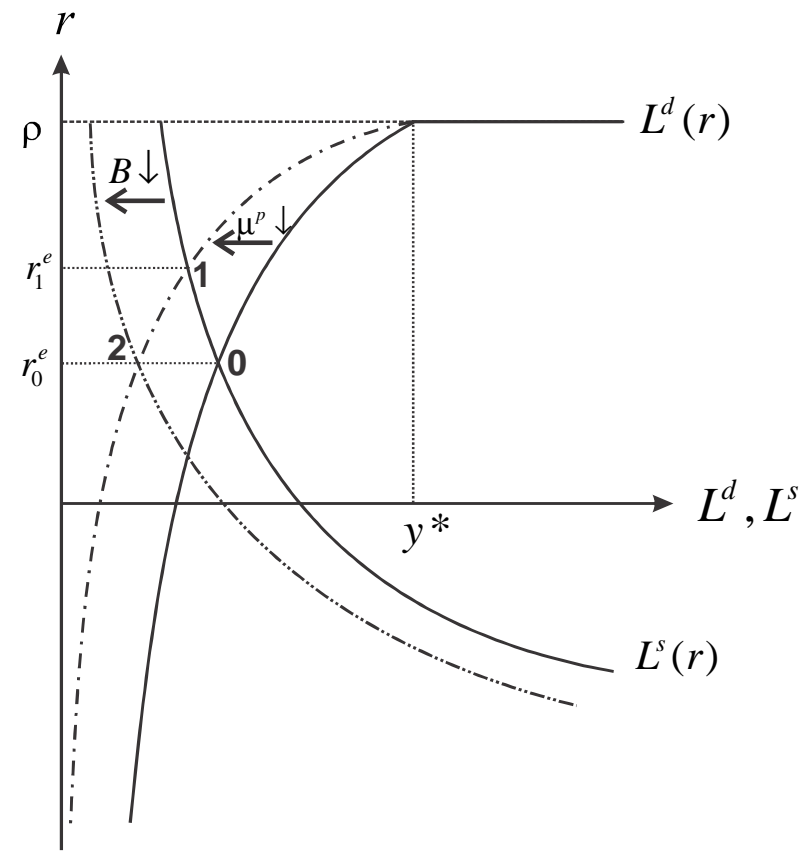

Figure 10: Negative shock on private liquidity

What are the policy responses to such a liquidity crisis? The policymaker can keep the interest rate on private claims constant so as to maintain the unemployment at its initial level by reducing the public liquidity in order to raise the liquidity premium of private assets. In Figure 10 the curve $L^{s}$ moves to the left in order to implement the new steady-state equilibrium denoted " 2 ". However, aggregate liquidity falls even more, which widens the rate-of-return difference between public and private liquidity and reduces the net output of the OTC market. Alternatively, the policymaker could increase the supply of public liquidity so as to keep the output of the OTC market constant, but this policy would raise the interest rate on private liquidity further and increase unemployment.

An alternative policy consists in committing to purchase the private assets at the price implied by the initial interest rate, $r$, i.e., $V_{F}=(\varphi-w) /(\delta+r)$, and to replace the private liquidity by public assets so as to keep $y^{p}=B+L^{p}$ unchanged. Because private assets have become less liquid, $\mu^{p \prime}<\mu^{p}$, their market price, $(\varphi-w) /\left(r^{\prime}+\delta\right)$ where $\rho-r^{\prime}=\sigma \mu^{p \prime}\left[f^{\prime}\left(y^{p}\right)-1\right]$, is less than the one offered by the policymaker. Consequently, all private assets are sold to the policymaker, i.e., the new supply of public liquidity is $B^{\prime}=y^{p}$. From (52) with $y^{p}=y^{g}$ and $\mu^{p}+\mu^{g}=1$ the interest rate on public liquidity is $\rho-r^{g}=\sigma\left[f^{\prime}\left(y^{p}\right)-1\right]$, which implies $r^{g}<r$. So the policymaker can finance the interest payment on public liquidity with the interest payment it collects on private assets. The state of the labor market is unchanged, and the output of the OTC market is increased. ${ }^{35}$

\footnotetext{
${ }^{35}$ In the presence of private information frictions such a policy might not be effective. For instance, Li, Rocheteau, and Weill (2012, Section 5) construct a model with endogenous resalability constraints due to a threat of fraudulent assets where an open-market policy that consists in purchasing partially-liquid assets with liquid ones ends up reducing
} 


\section{Firm heterogeneity and the effective liquidity of the economy}

We extend our model to endogenize the set of private assets that are eligible as collateral (or means of payment). For this, we introduce heterogeneity across private assets in terms of pledgeability (or resalability). The objective is twofold. First, we want to show that the main insights of our model are robust when only a subset of the private claims on firms' profits are part of the effective liquidity of the economy. Second, we want to illustrate how shocks or policies can lead to collateral expansion with implications for the labor market. We adopt the model from Section 6 with one type of public liquidity, real bonds, $\mu^{m}=0$ and let $\mathcal{M}=0$, where private assets are only partially acceptable as collateral, $\mu^{p} \leq 1$.

Suppose that when production starts - when the vacant job is matched with an unemployed worker - the type of the firm, $\omega \in[0,1]$, is drawn from a uniform distribution. The type, $\omega$, is a measure of the asset's fitness as collateral (e.g., redeployability of capital, credit rating, volatility, sensitivity to private information). ${ }^{36}$ To each type we associate a loan-to-value ratio, $\lambda(\omega) \in[0,1]$, that determines the fraction of the asset value that can be pledged - the buyer can obtain a loan of size $\lambda(\omega) a(\omega)$ if he commits $a(\omega)$ assets of type $\omega$ as collateral. The function, $\lambda(\omega)$, is continuous and increasing in $\omega$ with $\lambda(0)=0$ and $\lambda(1)=1 .^{37}$

In order for a private asset to be acceptable as collateral, it must be certified or rated by a third party (e.g., a credit rating agency). For simplicity, government bonds do not need to be certified. One can think of the certification requirement for private assets as an institutional constraint. Certification makes the type of an asset common-knowledge and it guarantees that the asset is not fraudulent. We assume that the certification process is costly because some information about the firm needs to be gathered. The certification cost in terms of the numéraire good is $\zeta>0 .{ }^{38}$ As before, in a fraction $\mu^{p}$ of matches all certified private assets are acceptable whereas in the remaining $1-\mu^{p}$ matches only public liquidity is acceptable.

aggregate liquidity.

${ }^{36}$ The relationship between the redeployability of capital (the value in its next best use) and asset liquidity is discussed in Shleifer and Vishny (1992).

${ }^{37}$ For tractability we followed Kiyotaki and Moore (2005) and kept the loan-to-value ratios, $\lambda(\omega)$, as exogenous. The monetary literature has provided several ways to endogenize such constraints. Rocheteau (2011) explains resalability constraints in a model of an OTC market where the asset holder has private information about the terminal value of the asset and uses asset retention as a signaling mechanism. In this model $\lambda$ is linked to the discrepancy of the values of the asset in different states. Li, Rocheteau, and Weill (2012) obtain a distribution of resalability constraints and haircuts in an OTC market where assets can be subject to fraudulent practices. The resalability of an asset depends on its specific cost of fraud and search frictions. For instance, the cost of fraud could be lower for firms with a lot of intangible assets. See, e.g., Giglio and Severo (2011) for the relationship between intangible capital and collateral shortages. Finally, Nosal and Rocheteau (2013) show that liquidity differences similar to the ones described in this section can emerge as the result of a pairwise Pareto-efficient bargaining protocol.

${ }^{38}$ This formalization is related to the costly-state-verification assumption introduced by Townsend (1979) and Williamson (1987). It is also related to the assumption in Lester, Postlewaite, and Wright (2012) according to which buyers of assets must incur a cost in order to be able to authenticate and accept an asset. Similarly, in Freeman and Kydland (2000) agents can make payments with money and demand deposits, but the use of the latter requires that the buyer incurs a fixed cost for his identity to be authenticated. 
Let $\Omega \subset[0,1]$ denote the set of assets that are certified, and let $\Omega^{c}$ denote the set of assets that are not certified. The budget constraint of the OTC-trader can be rewritten as:

$$
\dot{g}=\int_{\Omega} r(\omega) a(d \omega)+\int_{\Omega^{c}} \rho a(d \omega)+r^{g} g-\int \varepsilon(d \omega)-c-\Upsilon,
$$

where $a(d \omega)$ is the measure of assets of type $\omega \in d \omega$, and $\varepsilon(d \omega)$ is the investment in private assets of type $\omega \in d \omega$, with $\dot{a}(d \omega)=\varepsilon(d \omega)$. Assets that are not certified, $\omega \in \Omega^{c}$, are illiquid and pay an interest rate equal to $\rho$. Each unit of asset of type $\omega \in \Omega$, yields an interest payment equal to $r(\omega)$. The value function of the trader upon a match being formed is $Z[a(\omega), g]$ defined as before. The first-order condition, assuming an interior solution, is identical to (11),

$$
Z_{\omega}=1+\frac{\rho-r(\omega)}{\alpha}
$$

where $Z_{\omega}$ is the partial derivative with respect to $a(\omega)$. The marginal benefit from holding an asset of type $\omega$ net of its purchasing cost must be equal to its holding cost, which is the difference between the rate of time preference and the real interest rate on asset $\omega$.

The expected marginal benefit from holding an additional unit of asset $\omega$ in the OTC market is

$$
Z_{\omega}=\mu^{p} \lambda(\omega)\left[\frac{f^{\prime}\left(y^{p}\right)-1}{2}\right]+1, \quad \text { for all } \omega \in \Omega,
$$

where from the buyer-takes-all bargaining protocol the output traded in a bilateral match is

$$
y^{p}=\min \left\{\mathrm{A}+B, y^{*}\right\}
$$

We have used that $g=B$ from market clearing and $\mathrm{A}$ is the private liquidity of a trader,

$$
\mathrm{A}=\int_{\Omega} \lambda(\omega) a(d \omega)
$$

The right side of (70) has the following interpretation. With probability, $1 / 2$, the trader is the buyer in the bilateral match, and with probability, $\mu^{p}$, private assets are acceptable as collateral. A fraction $\lambda(\omega)$ of each unit of asset of type $\omega$ is pledgeable, which allows the trader to increase his surplus by $\lambda(\omega)\left[f^{\prime}\left(y^{p}\right)-1\right]$. So there are two sources of asset illiquidity. On the extensive margin, private assets are eligible as collateral in a fraction $\mu^{p}$ of all matches. On the intensive margin, conditional on being eligible, the buyer can only pledge a fraction $\lambda(\omega)$ of asset $\omega$.

The rate of return of asset $\omega$ conditional on being certified is obtained from (69) and (70),

$$
r(\omega)=\rho-\mu^{p} \lambda(\omega) \sigma\left[f^{\prime}\left(y^{p}\right)-1\right] .
$$

The second term on the right side of (73) is a liquidity premium that has both an asset specific component, $\lambda(\omega)$, and a component linked to aggregate liquidity, $y^{p}, \sigma$, and $\mu^{p}$. By a similar reasoning, the rate of return on public liquidity is

$$
r^{g}=\rho-\sigma\left\{\mu^{p}\left[f^{\prime}\left(y^{p}\right)-1\right]+\left(1-\mu^{p}\right)\left[f^{\prime}\left(y^{g}\right)-1\right]\right\},
$$


with

$$
y^{g}=\min \left\{B, y^{*}\right\} .
$$

The set of assets, $\Omega$, that are eligible as collateral is determined as follows. At the time when $\omega$ is realized, the firm decides whether or not to be certified, i.e., its maximization problem is

$$
\max \left\{V_{F}(\omega)-\zeta, \hat{V}_{F}\right\}
$$

where $V_{F}(\omega)=(\varphi-w) /[r(\omega)+\delta]$ is the value of the certified firm and $\hat{V}_{F}=(\varphi-w) /(\rho+\delta)$ is the value of a non-certified firm. Substituting $V_{F}(\omega)$ and $\hat{V}_{F}$ by their expressions, (76) becomes

$$
\max \left\{\frac{\varphi-w}{r(\omega)+\delta}-\zeta, \frac{\varphi-w}{\rho+\delta}\right\} .
$$

Therefore, the threshold for $\omega$ below which it is not optimal to certify the firm is $\hat{\omega}$ solution to $V_{F}(\hat{\omega})-\zeta \leq \hat{V}_{F}$ with an equality if $\hat{\omega}<1$, i.e.,

$$
\frac{\varphi-w}{r(\hat{\omega})+\delta}-\zeta \leq \frac{\varphi-w}{\rho+\delta}, \quad "=" \text { if } \hat{\omega}<1
$$

Notice that $\hat{\omega}>0$ since from $(73) r(0)=\rho$ and hence $V_{F}(0)=\hat{V}_{F}$. So there are always private claims that are illiquid. Substituting $r(\hat{\omega})$ by its expression given by (73) into (78), the loan-to-value ratio associated with the critical type, $\hat{\omega}$, is

$$
\lambda(\hat{\omega})=\min \left\{\frac{\zeta(\rho+\delta)^{2}}{\mu^{p} \sigma\left[f^{\prime}\left(y^{p}\right)-1\right][\zeta(\rho+\delta)+\varphi-w]}, 1\right\} .
$$

The set of assets that are accepted as collateral, $\Omega=[\hat{\omega}, 1]$, expands as $\mu$ or $\sigma$ increases, but shrinks as $y^{p}$ increases.

In order to determine the private liquidity, $\mathrm{A}$, and hence the output of the OTC market, $y^{p}$, we clear asset markets by requiring that $a(\omega)=n V_{F}(\omega)$ for all $\omega$, which from (2) and (72) implies

$$
\mathrm{A}=\int_{\hat{\omega}}^{1} \frac{\lambda(\omega) n(\theta)(\varphi-w)}{r(\omega)+\delta} d \omega
$$

where $\theta$ is determined by the free-entry condition,

$$
\begin{aligned}
\frac{\gamma}{q(\theta)} & =\int_{0}^{1} \max \left\{V_{F}(\omega)-\zeta, \hat{V}_{F}\right\} d \omega \\
& =\hat{\omega}\left(\frac{\varphi-w}{\rho+\delta}\right)+\int_{\hat{\omega}}^{1}\left[\frac{\varphi-w}{r(\omega)+\delta}-\zeta\right] d \omega .
\end{aligned}
$$

From (81) the average cost of opening a vacancy is equal to the expected value of a filled job, where the expectation is with respect to the firm's type that determines its interest rate.

Definition 3 A steady-state equilibrium is a list, $\left\langle\theta, \hat{\omega}, \mathrm{A}, y^{p}, y^{g}, r(\omega), r^{g}\right\rangle$, that solves (71), (73), (74), (75), (79), (80), and (81). 
We can reduce an equilibrium to a single equation in A as follows. Substituting $r(\omega)$ by its expression given by (73) into (81), $\theta$ is the solution to

$$
\frac{\gamma}{q(\theta)}=\max _{\hat{\omega}}\left\{\frac{\hat{\omega}(\varphi-w)}{\rho+\delta}+\int_{\hat{\omega}}^{1}\left[\frac{\varphi-w}{\rho+\delta-\mu^{p} \lambda(\omega) \sigma\left[f^{\prime}(\mathrm{A}+B)-1\right]^{+}}-\zeta\right] d \omega\right\},
$$

where $[x]^{+}=\max \{x, 0\}$. The market tightness defined by (82) is a continuous, nonincreasing function of private liquidity, $\theta=\theta(\mathrm{A})$, represented graphically in the bottom panel of Figure 11. Let $\mathrm{A}_{0}$ be a threshold for private liquidity defined as

$$
\mathrm{A}_{0}=\arg \min \left\{\mathrm{A} \geq 0: \mu^{p} \sigma\left[f^{\prime}(\mathrm{A}+B)-1\right]^{+} \leq \rho+\delta\right\}
$$

If $\mathrm{A}_{0}>0$, then the rate of return of the most liquid private asset, $\omega=1$, when $\mathrm{A}=\mathrm{A}_{0}$ is $r(1)=-\delta$. It follows that $\theta\left(\mathrm{A}_{0}\right)=+\infty$, and $n\left[\theta\left(\mathrm{A}_{0}\right)\right]=1$. Otherwise, $\theta(0) \geq \hat{\theta}$. Next, define $\mathrm{A}_{1}$ as the solution to

$$
\mathrm{A}_{1}=\arg \min \left\{\mathrm{A} \geq 0: \mu^{p} \sigma\left[f^{\prime}(\mathrm{A}+B)-1\right]^{+} \leq \frac{\zeta(\rho+\delta)^{2}}{\zeta(\rho+\delta)+\varphi-w}\right\} .
$$

From (79) and (84), for all $\mathrm{A} \geq \mathrm{A}_{1}$, it is not optimal for the firm owner to certify the firm, $\hat{\omega}=1$, and $\theta(\mathrm{A})=\hat{\theta}$. For all $\mathrm{A} \in\left(\mathrm{A}_{0}, \mathrm{~A}_{1}\right), \theta(\mathrm{A})>\hat{\theta}$ is decreasing in $\mathrm{A}$. From (83) and (84) it can be checked that $\mathrm{A}_{0} \leq \mathrm{A}_{1}$.

Next, we substitute $\theta(\mathrm{A})$ coming from (82) into (80) to determine A as the solution to

$$
\mathrm{A}=\int_{\hat{\omega}(\mathrm{A})}^{1} \frac{\lambda(\omega) n[\theta(\mathrm{A})](\varphi-w)}{\rho+\delta-\mu^{p} \lambda(\omega) \sigma\left[f^{\prime}(\mathrm{A}+B)-1\right]^{+}} d \omega .
$$

The right side of (85) is positive and decreasing in $\mathrm{A}$ for all $\mathrm{A} \in\left(\mathrm{A}_{0}, \mathrm{~A}_{1}\right)$ and it is equal to 0 when $\mathrm{A} \geq \mathrm{A}_{1}$. Hence, there is a unique solution, $\mathrm{A} \in\left[\mathrm{A}_{0}, \mathrm{~A}_{1}\right]$, to (80). Graphically, the right and left sides of (80) are represented by two curves labeled $R H S$ and $L H S$, respectively, in Figure 11. Given A, $\theta$ is uniquely determined by (82), $y$ is uniquely determined by (71) with $g=B$, and $\hat{\omega}$ is uniquely determined by (79). So there is a unique steady-state equilibrium.

Consider first equilibria where no private asset are used as collateral, $\hat{\omega}=1$ and $\mathrm{A}=0$. In this case all private assets are illiquid, $r(\omega)=\rho$ for all $\omega$, and $\theta=\hat{\theta}$. From (79) such an equilibrium exists if $\mathrm{A}_{1}=0$, i.e.,

$$
f^{\prime}(B)-1<\frac{\zeta(\rho+\delta)^{2}}{\mu^{p} \sigma[\zeta(\rho+\delta)+\varphi-w]} .
$$

The left side of (86) is a measure of the scarcity of public liquidity. If public liquidity is not too scarce, then private assets will not be part of the aggregate liquidity. As $\mu$ and $\sigma$ increase, the use of private assets as collateral becomes more likely.

If (86) does not hold, then some private assets are used as collateral. In this context we investigate how changes in fundamentals and policy affect the set of private assets that are used as collateral, $\Omega$, and labor market outcomes. Suppose first that the policymaker raises the supply 


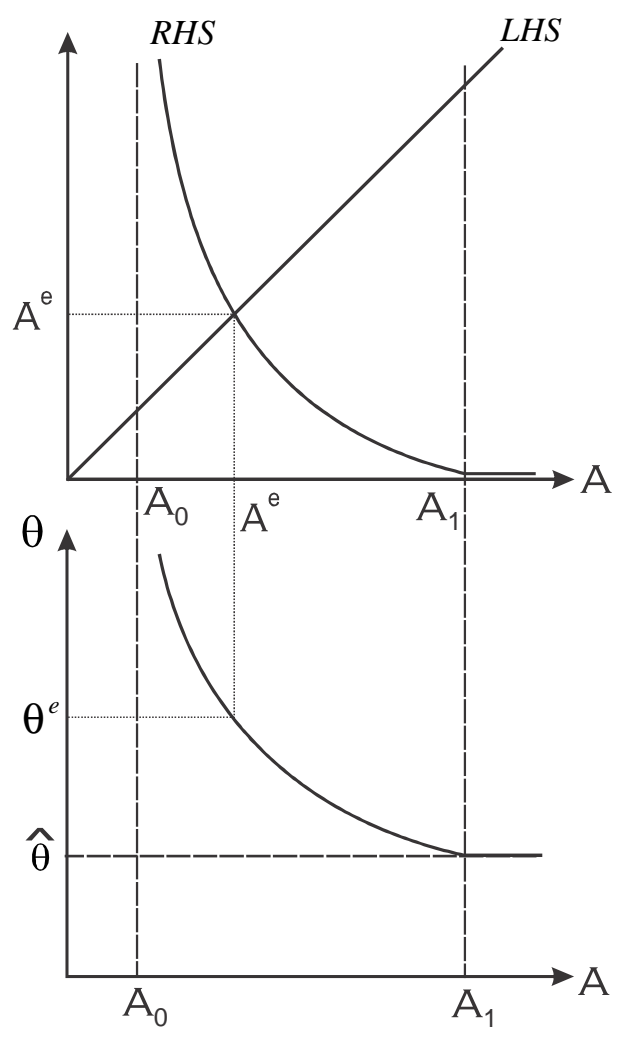

Figure 11: Determination of the equilibrium values of $\mathrm{A}$ and $\theta$

of public liquidity, $B$. The right side of (85) decreases so that A is lower and $y^{p}$ is higher. Interest rates on liquid assets are higher and the set of eligible assets is smaller, i.e., $\hat{\omega}$ increases. From (82) the fact that $\sigma\left[f^{\prime}\left(y^{p}\right)-1\right]^{+}$decreases implies that market tightness decreases and unemployment increases. These results provide another example of public liquidity crowding out private liquidity. However, public liquidity also raises the average quality of assets (as measured by $\hat{\omega}$ ) used as collateral and saves on certification costs. ${ }^{39}$ (The sum of all certification costs in a steady-state equilibrium is $\delta n(\theta)(1-\hat{\omega})$.)

Consider next a shock that raises the demand for collateral, e.g., an increase in $\sigma$. The right side of (85) increases, which leads to an increase in private liquidity, A. By the same logic as above, the output in the OTC market, $y$, increases, the set of private assets used as collateral expands, and interest rates decrease. ${ }^{40}$ From $(73)$ the rate-of-return difference between two liquid assets $\omega$

\footnotetext{
${ }^{39}$ This result is in accordance with an old idea in monetary theory according to which money is a substitute for investment in information because it is recognizable. See Brunner and Meltzer (1971) for one of the very first statement of this idea.

${ }^{40}$ As an example of collateral expansion, before 2012 the Chicago Mercantile Exchange (CME) Group only accepted corporate bonds as collateral for futures. Since March 2012, CME allows corporate bonds to serve as collateral for OTC interest rate swaps (with a 20 percent haircut).
} 


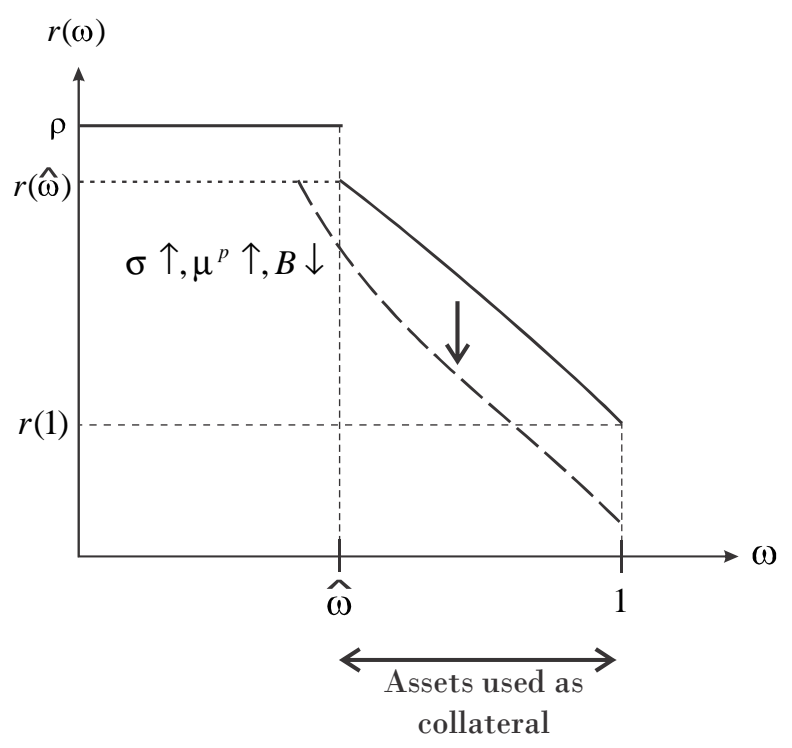

Figure 12: Liquidity structure of asset returns

and $\omega^{\prime}>\omega$ in $[\hat{\omega}, 1]$ is

$$
r(\omega)-r\left(\omega^{\prime}\right)=\left[\lambda\left(\omega^{\prime}\right)-\lambda(\omega)\right] \mu \sigma\left[f^{\prime}\left(y^{p}\right)-1\right] .
$$

As $\sigma$ increases these differences widen (because $\sigma\left[f^{\prime}\left(y^{p}\right)-1\right]$ increases). Graphically, in Figure 12 the curve representing the distribution of interest rates, $r(\omega)$, moves downward. As a result of lower interest rates, the number of firms increases and unemployment decreases.

Finally, suppose that the fraction of OTC transactions where private assets are acceptable as collateral, $\mu^{p}$, decreases. The right side of (85) decreases, which leads to a decrease in private liquidity, A. The effects are opposite to those described above: the set of private assets used as collateral shrinks, interest rates go up, market tightness decreases, and unemployment increases. So there is destruction of private liquidity both because fewer firms enter the market and because there is a flight to quality, $\hat{\omega}$ increases.

\section{Intermediation and liquidity}

So far we have assumed that the output of the OTC sector has no direct spillover to the labor market. In the following we relax this assumption by introducing a new channel through which the activity of traders in the OTC market benefits the real economy and the labor market. We will assume that the speed at which firms get access to funds depends on the measure of OTC-traders, which itself depends on the effective liquidity of the economy.

We assume that it takes time for firms/entrepreneurs to access the market to find funds, which 
aims to capture search-like frictions in the credit market. ${ }^{41}$ This search process is formalized by a Poisson process with arrival rate $\beta(\psi)>0$, where $\beta(\psi)$ is an increasing function of the measure of OTC-traders, $\psi \cdot{ }^{42}$ So the larger the number of OTC-traders in the market, the faster it is for firms to find funding, i.e., the higher the liquidity of the credit market.

The measure of OTC-traders, $\psi$, is endogenous. We assume that each trader has an outside option that consists of producing a flow of numéraire good, $\varsigma$, per unit of time. (One can think of $\varsigma$ as a measure of the investment opportunities of the trader.) So by participating in the market the trader gives up $\varsigma / \rho$. The cumulative distribution of $\varsigma$ across traders is $G(\varsigma) .{ }^{43}$ Traders' activities in the OTC market can be interpreted as resulting from their role in financing the real economy, e.g., hedging and insurance contracts following the attribution of loans or the provision of payment/clearing services. Hence, a more abundant liquidity raises the surplus of traders, which reduces their effective participation cost to the market for loanable funds.

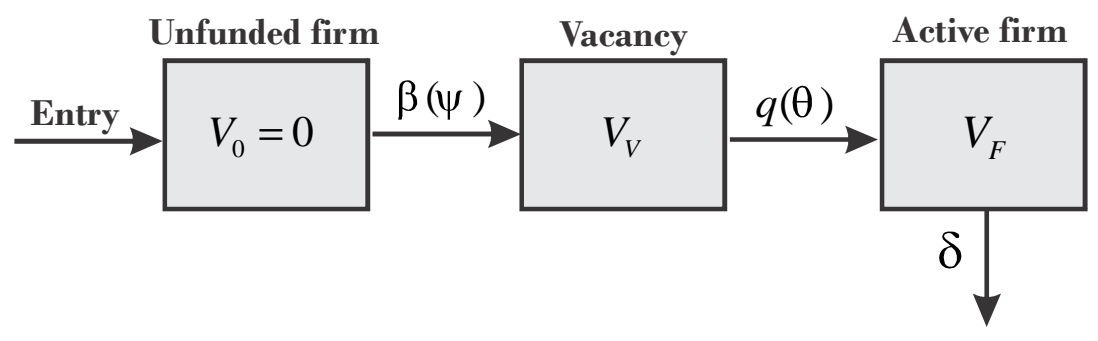

Figure 13: Frictions in the credit market

As indicated in Figure 13, a firm that enters the market can start its hiring activity only after it has accessed the market for loanable funds. When searching for funds, a firm incurs a nonpecuniary flow cost $\kappa>0$ that captures the effort and pain of the entrepreneur to access the market for loanable funds.

Firms find it optimal to look for funds if the search cost, $\kappa$, is not greater than the arrival rate of a funding opportunity, $\beta(\psi)$, times the value of a vacancy, $V_{V}$. In equilibrium the value of a vacant job is $V_{V}=\kappa / \beta(\psi)>0$. We assume that only claims on filled jobs can be authenticated as genuine and are acceptable as collateral. As a result claims on vacant jobs are illiquid and their

\footnotetext{
${ }^{41}$ For related formalizations of competitive markets with search-like frictions see, e.g., Lucas and Prescott (1974), Rocheteau and Wright (2005), and Pagnotta and Philippon (2011). It is also related to the description of a competitive interdealer market in the model of an OTC market of Duffie, Garleanu, and Pedersen (2005). This formalization allows us to avoid the bargaining problem between the entrepreneur and the OTC-trader.

${ }^{42}$ This formalization of delays to access the credit market is related to the one in Wasmer and Weil (2004) except that we do not assume two-sided search. In our model, only firms must spend time to access a competitive credit market. One formalization is also related to the search markets for venture capital as in Inderst and Müller (2004), Michelacci and Suarez (2004), and Boadway, Secrieru, and Vigneault (2005).

${ }^{43}$ This formalization of the participation decision is similar to the one in Pissarides (2000, Chapter 7).
} 
interest rate is $\rho$. The flow Bellman equation for a vacancy is

$$
\rho V_{V}=-\gamma+q\left(V_{F}-V_{V}\right)
$$

From the free-entry condition, $V_{V}=\kappa / \beta(\psi)$, and (88) the value of a vacant job

$$
V_{V}=\frac{-\gamma+q(\theta) V_{F}}{\rho+q(\theta)}=\frac{\kappa}{\beta(\psi)},
$$

where $V_{F}=(\varphi-w) /(r+\delta)$. Provided that $V_{F}>\kappa / \beta(\psi)$, (89) determines a unique $\theta>0$. Market tightness increases with $\beta(\psi)$ but decreases with $r$. The aggregate private liquidity is defined as before, $L^{p}(\theta, r ; \psi)=n(\theta) V_{F}$ where from $(4) n(\theta)=p(\theta) /[\delta+p(\theta)]$.

We now turn to the measure of OTC-traders in the market, $\psi$. The lifetime expected utility of a trader who participates in the market, $W(a, g)$, is given by the following flow Bellman equation:

$$
\rho W(a, g)=\sigma \mu^{p}\{f[y(a+g)]-y(a+g)\}+\sigma\left(1-\mu^{p}\right)\{f[y(g)]-y(g)\}+r a+r^{g} g .
$$

According to the first two terms on the right side of (90) the trader enjoys the surpluses from transactions in unrestricted and restricted matches. In unrestricted matches both public and private assets are eligible as collateral (first term), while in restricted matches only public assets are eligible (second term). The last two terms on the right side of (90) are the flow returns on private and public assets. The optimal portfolio maximizes $W(a, g)-(a+g)$.

An OTC-trader is willing to participate in the market if $\varsigma \leq \rho \max _{a, g}\{W(a, g)-(a+g)\}$, i.e., $\varsigma \leq \hat{\varsigma}$ where

$$
\hat{\varsigma} \equiv \max _{a, g}\left\{\sigma \mu^{p}\{f[y(a+g)]-y(a+g)\}+\sigma\left(1-\mu^{p}\right)\{f[y(g)]-y(g)\}-(\rho-r) a-\left(\rho-r^{g}\right) g\right\} .
$$

The opportunity cost below which it is optimal to participate in the market for loanable funds, $\hat{\varsigma}$, is equal to the expected surplus of the trader net of the cost of holding the optimal portfolio of liquid assets. The measure of participating traders is equal to the measure of traders with an opportunity cost less than $\hat{\varsigma}$, i.e., $\psi=G(\hat{\varsigma})$. From market clearing $\psi a=L^{p}=n V_{F}$ and $\psi g=B$. Therefore, the quantities traded in OTC matches are $y^{p}=y\left(n V_{F} / \psi+B / \psi\right)$ and $y^{g}=y(B / \psi)$, i.e.,

$$
\begin{aligned}
y^{p} & =\min \left\{y^{*}, \frac{p(\theta)(\varphi-w)}{[\delta+p(\theta)](r+\delta) G(\hat{\varsigma})}+\frac{B}{G(\hat{\varsigma})}\right\} \\
y^{g} & =\min \left\{y^{*}, \frac{B}{G(\hat{\varsigma})}\right\} .
\end{aligned}
$$

Definition 4 A steady-state equilibrium is a list, $\left(\theta, y^{p}, y^{g}, r, r^{g}, \hat{\varsigma}\right)$, that solves (51)-(52), (89), (91), and (92)-(93).

Suppose first that public liquidity is abundant, i.e., $g \geq y^{*}$. Then, from (92)-(93) $y^{g}=y^{p}=y^{*}$, from (51)-(52) $r=r^{g}=\rho$ and, from (91), $\hat{\varsigma}=\sigma\left[f\left(y^{*}\right)-y^{*}\right]$. The condition for this equilibrium to exist is $B \geq G(\hat{\varsigma}) y^{*}$. 
Suppose next that liquidity is only abundant in unrestricted matches, $a+g \geq y^{*}>g$. It follows from (92)-(93) that $y^{g}<y^{p}=y^{*}$ and from (51)-(52) $r^{g}<r=\rho$. From (91) the demand for public liquidity, $G(\hat{\varsigma}) g$, is increasing with $r^{g}$. An increase in $B$ raises $r^{g}, \hat{\varsigma}$, and $\psi$. When liquidity is more abundant, OTC-traders enjoy larger surpluses in the OTC market and hence they have higher incentives to participate. As a result of the larger OTC market, firms have a better access to funds, i.e., $\beta(\psi)$ increases. The expected cost of searching for funds, $\kappa / \beta(\psi)$, decreases, which raises market tightness and reduces unemployment. This result illustrates how a more abundant liquidity can have a positive effect on employment by reducing intermediation costs. It also shows that public liquidity does not necessarily crowd private liquidity out.

In Figure 14 we present a numerical example that illustrates the effects of a change in public liquidity on labor market outcomes $(\theta$ and $u$ ), participation in the OTC market $(\psi)$, and the interest rate $(r) .{ }^{44}$ The parameter values and functional forms are taken as follows. The unit of time is taken to be a year and $\rho=0.05$. The output of a firm-worker match, $\varphi$, is normalized to 1 , and $w=0.85$. The flow of hires is $h(u, v)=1.1 u^{0.5} v^{0.5}$ and the separation rate is $\delta=0.1$. The flow cost of advertising a vacancy is $\gamma=0.5$ and the cost of searching for funds is $\kappa=0.5$. Firms access funds at Poisson rate $\beta(\psi)=\psi$. The outside option for OTC-traders, $\varsigma$, is uniformly distributed in the interval $\left[0, \varsigma_{\max }\right]$ where $\varsigma_{\max }=\sigma\left[f\left(y^{*}\right)-y^{*}\right]$. It follows that $\psi=1$ for all $B \geq y^{*}$. Traders become buyers at Poisson rate $\sigma=1$ and their utility is $f(y)=7.5 y^{0.2}$. Given that $y^{*}$ solves $f^{\prime}\left(y^{*}\right)=1$, the assumed parameters imply $y^{*}=1.66$ and $\varsigma_{\max }=6.64$. The eligibility of private assets is $\mu^{p}=0.4$.

In each of the four panels in Figure 14 we distinguish three cases: (i) abundant public liquidity $\left(g \geq y^{*}\right)$; (ii) abundant liquidity in unrestricted matches $\left(a+g \geq y^{*}>g\right)$; (iii) scarce liquidity $\left(a+g<y^{*}\right)$. When public liquidity is abundant, labor market outcomes are independent of public liquidity, the measure of OTC traders is maximum and equal to $\psi=1$, and the real interest rate is maximum and equal to $r=\rho=0.05$. When liquidity is abundant in unrestricted matches only, $a+g \geq y^{*}$ but $g<y^{*}$, then the measure of OTC traders increases with the provision of public liquidity. As a result, market tightness increases with $B$ whereas unemployment decreases with $B$. So in this regime private liquidity increases with the supply of public liquidity. The real interest rate is still equal to $r=\rho=0.05$. When liquidity is scarce in all matches, $a+g<y^{*}$, an increase in public liquidity has non-monotonic effects on labor market outcomes. On the one hand a higher supply of public liquidity raises the interest rate, $r$, and reduces the value of filled jobs, $V_{F}$. On the other hand it raises participation in the OTC market, allowing firms to be funded more quickly. For low values of $B$ the second effect dominates so that market tightness increases and unemployment decreases as $B$ increases. For larger values of $B$ the first effect dominates and hence labor market tightness decreases and unemployment increases as $B$ increases.

\footnotetext{
${ }^{44}$ For our numerical example, the equilibrium is unique. However, the equilibrium does not need to be unique for all functional forms and parameter values.
} 


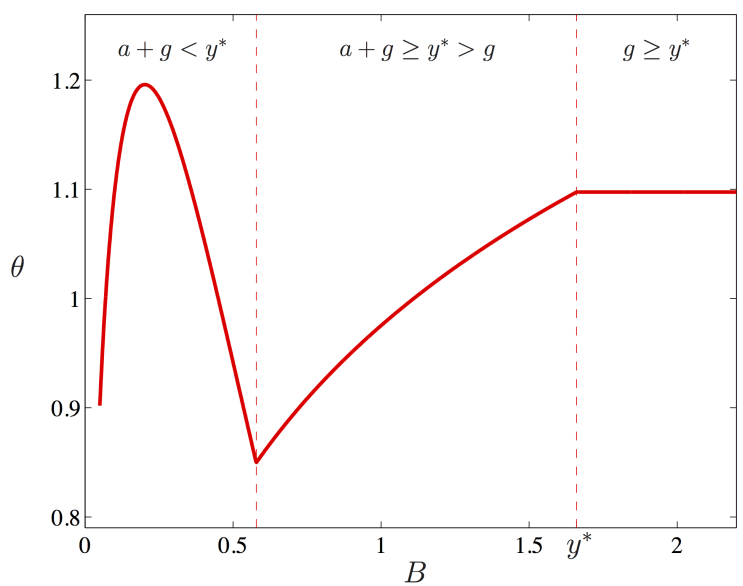

(a) Labor market tightness

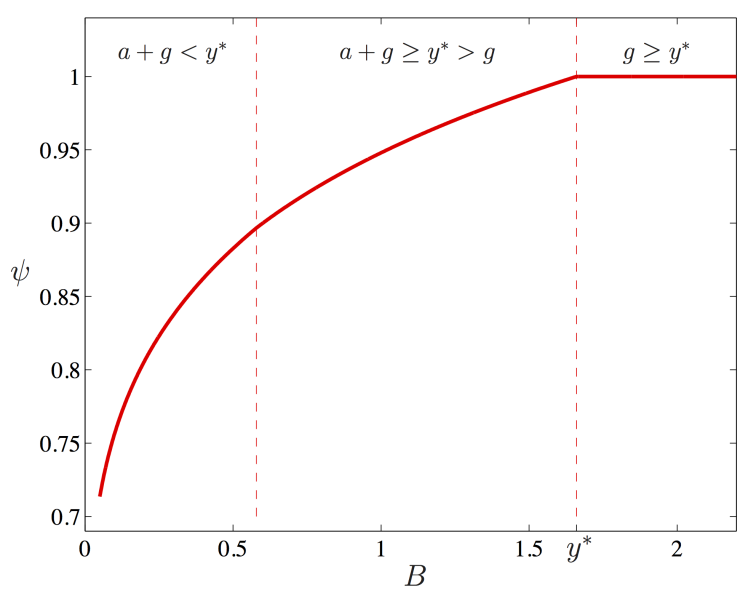

(c) Measure of OTC-traders

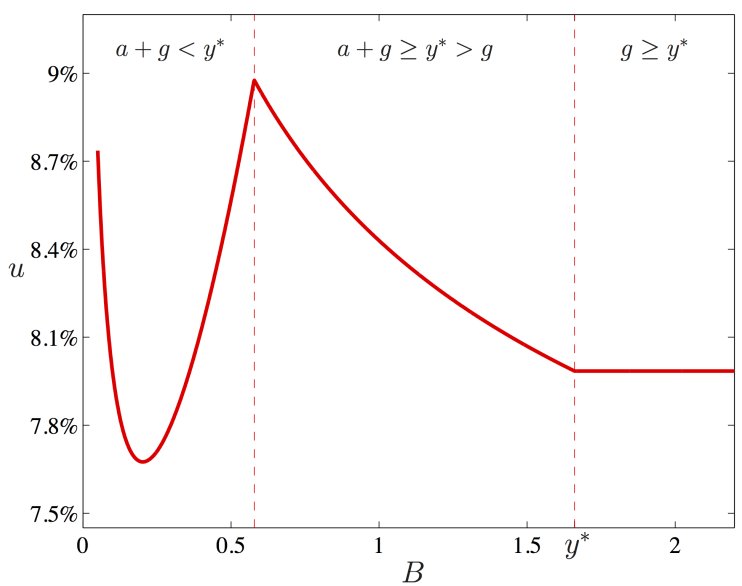

(b) Unemployment rate

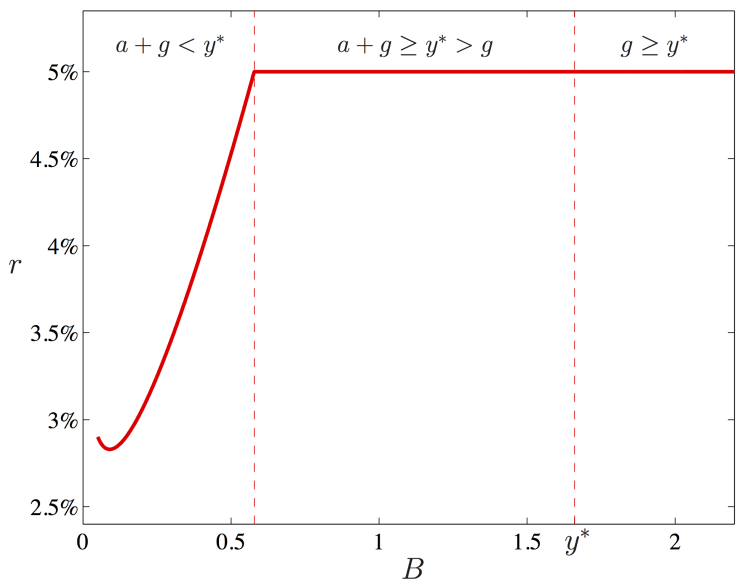

(d) Private-assets interest rate

Figure 14: Effects of an increase in public liquidity

\section{Conclusion}

We have developed a tractable model of liquidity provision and the labor market by introducing an explicit market for liquidity into the canonical model of equilibrium unemployment of Mortensen and Pissarides (1994). Our model allowed us to study the interactions between the key missions of a monetary authority: providing liquidity to the financial sector, households, and firms, and keeping interest rates moderate to achieve full employment.

In terms of policies, we showed that in our benchmark model an increase in public liquidity crowds private liquidity out and raises interest rates and unemployment. The same outcome occurs under an open-market operation that raises the supply of nominal government bonds relative to the supply of fiat money. In contrast, an increase in the inflation rate reduces the real interest rate and leads to more job creation and a lower unemployment rate. More generally, we identified a trade-off between liquidity provision and the objective of keeping moderate interest rates for the 
private sector. Under some conditions this trade-off makes it optimal to keep liquidity scarce in order to reduce an inefficiently high unemployment rate.

We extended our model to add a channel through which the provision of liquidity to the OTC sector could mitigate search-like frictions in credit markets. In that version of the model an increase in public liquidity raises the expected surplus of participants in the OTC market leading to more entry. As the number of the OTC-traders increases, firms can access funds more rapidly, which may promote job creations and cause a decline in unemployment. We provided a numerical example to illustrate the non-monotonic relationship between liquidity provision and unemployment.

In terms of financial stability we studied flight-to-liquidity events triggered by a lower acceptability of some assets as collateral due, for instance, to severe informational asymmetries regarding the quality of assets. The interest rate on private assets increases along with the rate-of-return differential between private and public liquidity, and unemployment rises. The government can mitigate this shock by offering to purchase private assets at their pre-crisis price. Regulations that raise collateral requirements in OTC transactions reduce interest rates and unemployment. If assets are heterogeneous in terms of their ability to serve as collateral, then an increase in collateral requirements leads to lower unemployment and collateral expansion. 


\section{References}

Alvarez, F., And F. Lippi (2013): "The Demand of Liquid Assets with Uncertain Lumpy Expenditures," Journal of Monetary Economics, forthcoming.

Andolfatto, D. (1996): "Business Cycles and Labor-Market Search," American Economic Review, 86(1), 112-132.

Angeletos, G.-M., F. Collard, H. Dellas, and B. Diba (2013): "Optimal Public Debt Management and Liquidity Provision," Discussion Paper 18800, National Bureau of Economic Research.

Atkeson, A. G., A. L. Eisfeldt, and P.-O. Weill (2013): "The Market for OTC Credit Derivatives," University of California, Los Angeles.

Bean, C., and C. Pissarides (1993): "Unemployment, Consumption and Growth," European Economic Review, 37(4), 837-854.

Berentsen, A., G. Menzio, and R. Wright (2011): "Inflation and Unemployment in the Long Run," American Economic Review, 101(1), 371-398.

Berentsen, A., G. Rocheteau, and S. Shi (2007): "Friedman Meets Hosios: Efficiency in Search Models of Money," Economic Journal, 117(516), 174-195.

BIS (2001): Collateral in Wholesale Financial Markets: Recent Trends, Risk Management and Market Dynamics. Committee on the Global Financial System.

(2013): Statistical Release: OTC Derivatives Statistics at End-December 2012. Monetary and Economic Department.

Boadway, R., O. Secrieru, and M. Vigneault (2005): "A Search Model of Venture Capital, Entrepreneurship, and Unemployment," Working Papers 05-24, Bank of Canada.

Brunner, K., and A. H. Meltzer (1971): "The Uses of Money: Money in the Theory of an Exchange Economy," American Economic Review, 61(5), 784-805.

Brunnermeier, M. K., and L. H. Pedersen (2009): "Market Liquidity and Funding Liquidity," Review of Financial Studies, 22(6), 2201-2238.

Caballero, R. J., and E. Farhi (2013): "A Model of the Safe Asset Mechanism (SAM): Safety Traps and Economic Policy," NBER Working Papers 18737, National Bureau of Economic Research.

Cooley, T. F., and V. Quadrini (2004): "Optimal Monetary Policy in a Phillips-Curve World," Journal of Economic Theory, 118(2), 174-208.

Dick-Nielsen, J., P. Feldhütter, and D. Lando (2012): "Corporate Bond Liquidity Before and After the Onset of the Subprime Crisis," Journal of Financial Economics, 103(3), 471-492.

Duffie, D., N. Garleanu, and L. H. Pedersen (2005): "Over-the-Counter Markets," Econometrica, 73(6), 1815-1847.

$1865-1900$.

Ferraris, L., and M. Watanabe (2008): "Collateral Secured Loans in a Monetary Economy," Journal of Economic Theory, 143(1), 405-424. 
Freeman, S., and F. E. Kydland (2000): "Monetary Aggregates and Output," American Economic Review, 90(5), 1125-1135.

Geromichalos, A., and L. Herrenbrueck (2013): "Monetary Policy, Asset Prices, and Liquidity in Over-the-Counter Markets," University of California, Davis.

Giglio, S., And T. Severo (2011): "Intangible Capital, Relative Asset Shortages and Bubbles," IMF Working Papers 11/271, International Monetary Fund.

Gorton, G., S. Lewellen, and A. Metrick (2012): "The Safe-Asset Share," American Economic Review: Papers $\&$ Proceedings, 102(3), 101-106.

Gorton, G., And A. Metrick (2010): "Haircuts," Federal Reserve Bank of St. Louis Review, $92(6), 507-519$.

Gorton, G. B., and G. Ordoñez (2013): "The Supply and Demand for Safe Assets," NBER Working Papers 18732, National Bureau of Economic Research.

Gourinchas, P.-O., and O. Jeanne (2012): "Global Safe Assets," Discussion paper, University of California, Berkeley.

Guerrieri, V., and R. Shimer (2012): "Dynamic Adverse Selection: A Theory of Illiquidity, Fire Sales, and Flight to Quality," NBER Working Papers 17876, National Bureau of Economic Research.

Guerrieri, V., R. Shimer, and R. Wright (2010): "Adverse Selection in Competitive Search Equilibrium," Econometrica, 78(6), 1823-1862.

Holmström, B., and J. Tirole (1998): "Private and Public Supply of Liquidity," Journal of Political Economy, 106(1), 1-40.

- (2011): Inside and Outside Liquidity. MIT Press.

Hosios, A. J. (1990): "On the Efficiency of Matching and Related Models of Search and Unemployment," Review of Economic Studies, 57(2), 279-98.

Hu, T.-W., J. Kennan, and N. Wallace (2009): "Coalition-Proof Trade and the Friedman Rule in the Lagos-Wright Model," Journal of Political Economy, 117(1), 116-137.

IMF (2012): Global Financial Stability Report: The Quest for Lasting Stability. World Economic and Financial Surveys.

Inderst, R., And H. M. MÜLler (2004): "The Effect of Capital Market Characteristics on the Value of Start-up Firms," Journal of Financial Economics, 72(2), 319-356.

ISDA (1996): Guidelines for Collateral Practitioners. International Swaps and Derivatives Association.

(2010): Market Review of OTC Derivative Bilateral Collateralization Practices. International Swaps and Derivatives Association.

- (2012): OTC Derivatives Market Analysis Mid-Year 2012. International Swaps and Derivatives Association.

Kim, Y. S. (1996): "Money, Barter, and Costly Information Acquisition," Journal of Monetary Economics, 37(1), 119-142. 
Kiyotaki, N., And J. Moore (2005): "Financial Deepening," Journal of the European Economic Association, 3(2-3), 701-713.

Koeppl, T., C. Monnet, and T. Temzelides (2008): "A Dynamic Model of Settlement," Journal of Economic Theory, 142(1), 233-246.

Krishnamurthy, A., and A. Vissing-Jorgensen (2012): "The Aggregate Demand for Treasury Debt," Journal of Political Economy, 120(2), 233-267.

_ (2013): "Short-term Debt and Financial Crises: What we can learn from U.S. Treasury Supply," Northwestern University.

Lagos, R. (2010a): "Asset Prices and Liquidity in an Exchange Economy," Journal of Monetary Economics, 57(8), 913-930.

(2010b): "Some Results on the Optimality and Implementation of the Friedman Rule in the Search Theory of Money," Journal of Economic Theory, 145(4), 1508-1524.

(2011): "Asset Prices, Liquidity, and Monetary Policy in an Exchange Economy," Journal of Money, Credit and Banking, 43, 521-552.

Lagos, R., and G. Rocheteau (2007): "Search in Asset Markets: Market Structure, Liquidity, and Welfare," American Economic Review: Papers 85 Proceedings, 97(2), 198-202.

(2008): "Money and Capital as Competing Media of Exchange," Journal of Economic Theory, 142(1), 247-258.

(2009): "Liquidity in Asset Markets With Search Frictions," Econometrica, 77(2), 403-426.

Lagos, R., And R. Wright (2005): "A Unified Framework for Monetary Theory and Policy Analysis," Journal of Political Economy, 113(3), 463-484.

Lehmann, E. (2012): “A Search Model of Unemployment and Inflation," Scandinavian Journal of Economics, 114(1), 245-266.

Lester, B., A. Postlewaite, and R. Wright (2012): "Information, Liquidity, Asset Prices, and Monetary Policy," Review of Economic Studies, 79(3), 1209-1238.

Li, Y., G. Rocheteau, and P.-O. Weill (2012): "Liquidity and the Threat of Fraudulent Assets," Journal of Political Economy, 120(5), 815-846.

Lucas, R., And E. Prescott (1974): "Equilibrium Search and Unemployment," Journal of Economic Theory, 7(2), 188-209.

Merz, M. (1995): "Search in the Labor Market and the Real Business Cycle," Journal of Monetary Economics, 36(2), 269-300.

Michelacci, C., And J. Suarez (2004): "Business Creation and the Stock Market," Review of Economic Studies, 71(2), 459-481.

Mortensen, D. T., and C. A. Pissarides (1994): "Job Creation and Job Destruction in the Theory of Unemployment," Review of Economic Studies, 61(3), 397-415.

Nosal, E., and G. Rocheteau (2013): "Pairwise Trade, Asset Prices, and Monetary Policy," Journal of Economic Dynamics and Control, 37(1), 1-17. 
Pagnotta, E., And T. Philippon (2011): "Competing on Speed," NBER Working Paper 17652, National Bureau of Economic Research.

Petrosky-Nadeau, N. (2013): "TFP during a Credit Crunch," Journal of Economic Theory, 148(3), 1150-1178.

Petrosky-Nadeau, N., and E. Wasmer (2013): "The Cyclical Volatility of Labor Markets under Frictional Financial Markets," American Economic Journal: Macroeconomics, 5(1), 193-221.

Pissarides, C. A. (2000): Equilibrium Unemployment Theory. MIT press, Cambridge, MA.

Reinhart, C. M., and K. S. Rogoff (2013): "Shifting Mandates: The Federal Reserve's First Centennial," American Economic Review: Papers $\& 5$ Proceedings, 103(3), 48-54.

Rocheteau, G. (2011): "Payments and Liquidity under Adverse Selection," Journal of Monetary Economics, 58(3), 191-205.

(2012): "The Cost of Inflation: A Mechanism Design Approach," Journal of Economic Theory, 147(3), 1261-1279.

Rocheteau, G., and R. Wright (2005): "Money in Search Equilibrium, in Competitive Equilibrium, and in Competitive Search Equilibrium," Econometrica, 73(1), 175-202.

(2013): "Liquidity and Asset Market Dynamics," Journal of Monetary Economics, 60(2), $275-294$

Seierstad, A., and K. Sydsaeter (1987): Optimal Control Theory with Economic Applications. North-Holland, Amsterdam.

SHI, S. (1995): "Money and Prices: A Model of Search and Bargaining," Journal of Economic Theory, 67(2), 467-496.

ShI, S. (1997): “A Divisible Search Model of Fiat Money," Econometrica, 65(1), 75-102.

(1998): "Search for a Monetary Propagation Mechanism," Journal of Economic Theory, $81(2), 314-352$.

Shleifer, A., and R. W. Vishny (1992): "Liquidation Values and Debt Capacity: A Market Equilibrium Approach," Journal of Finance, 47(4), 1343-1366.

Tobin, J. (1965): "Money and Economic Growth,” Econometrica, 33(4), 671-684.

Townsend, R. M. (1979): "Optimal Contracts and Competitive Markets with Costly State Verification," Journal of Economic Theory, 21(2), 265-293.

Trejos, A., And R. Wright (1995): "Search, Bargaining, Money, and Prices," Journal of Political Economy, 103(1), 118-141.

Uren, L. (2013): "Equilibrium Unemployment with Incomplete Markets," University of Melbourne.

Wasmer, E., And P. Weil (2004): "The Macroeconomics of Labor and Credit Market Imperfections," American Economic Review, 94(4), 944-963.

Weill, P.-O. (2007): "Leaning Against the Wind," Review of Economic Studies, 74(4), 1329-1354. 
Williamson, S. D. (1987): "Costly Monitoring, Loan Contracts, and Equilibrium Credit Rationing," Quarterly Journal of Economics, 102(1), 135-146.

(2012): "Sorting Out Keynesian Economics: A New Monetarist Approach," Washington University in St. Louis.

(2013): "Liquidity, Monetary Policy, and the Financial Crisis: A New Monetarist Approach," American Economic Review, forthcoming.

Wilson, C. (1979): "An Infinite Horizon Model with Money," in General Equilibrium, Growth, and Trade: Essays in Honor of Lionel McKenzie, ed. by J. R. Green, and J. A. Scheinkman, pp. 81-104. Academic Press, New York.

Woodford, M. (1990): "Public Debt as Private Liquidity," American Economic Review, 80(2), $382-388$.

Zhu, T., and N. Wallace (2007): "Pairwise Trade and Coexistence of Money and Higher-Return Assets," Journal of Economic Theory, 133(1), 524-535. 


\section{A1. Endogenous wage}

We endogenize the wage following the same methodology as in the standard Mortensen-Pissarides model. The wage is the outcome of a bilateral negotiation between a worker and the firm he is matched with. We assume that this outcome is given by the generalized Nash solution where the worker's bargaining power is $\varpi \in[0,1]$, i.e.,

$$
w=\arg \max \left[V_{E}(w)-V_{U}\right]^{\varpi}\left[V_{F}(w)\right]^{1-\varpi},
$$

where $V_{E}(w)$ is the lifetime expected discounted utility of a worker employed at the wage $w$ and $V_{U}$ is the lifetime expected discounted utility of an unemployed worker. The flow Bellman equation for the value function of a worker employed at the wage $w$ is

$$
\rho V_{E}(w)=w-\delta\left[V_{E}(w)-V_{U}\right]
$$

According to (95) an employed worker receives a wage $w$ per unit of time and he gets separated from his job according to a Poisson process with arrival rate $\delta$. From (95) we compute the worker's surplus as:

$$
V_{E}(w)-V_{U}=\frac{w-\rho V_{U}}{\rho+\delta}
$$

The surplus of a firm is $V_{F}(w)=(\varphi-w) /(r+\delta)$. Substituting these expressions into the Nash product we obtain

$$
w=\arg \max \left(w-\rho V_{U}\right)^{\varpi}(\varphi-w)^{1-\varpi}
$$

The solution to (97) is

$$
w=\varpi \varphi+(1-\varpi) \rho V_{U} .
$$

As it is standard in the Mortensen-Pissarides model, the wage is a weighted average of the productivity and the worker's reservation wage, $\rho V_{U}$.

Let us turn to the determination of the worker's reservation wage. The flow Bellman equation for the value of an unemployed worker is

$$
\rho V_{U}=p\left(V_{E}-V_{U}\right)
$$

From (99) an unemployed worker finds a job at Poisson rate $p$, in which case he enjoys the surplus $V_{E}-V_{U}$. From the bargaining solution, (97), the surpluses of the worker and the firm are related by the following equation:

$$
\begin{aligned}
V_{E}-V_{U} & =\frac{\varpi}{1-\varpi}\left(\frac{r+\delta}{\rho+\delta}\right) V_{F} \\
& =\frac{\varpi}{1-\varpi}\left(\frac{r+\delta}{\rho+\delta}\right) \frac{\gamma}{q(\theta)}
\end{aligned}
$$

Substituting this expression into (99) one obtains

$$
\rho V_{U}=\frac{\varpi}{1-\varpi}\left(\frac{r+\delta}{\rho+\delta}\right) \theta \gamma
$$


So the reservation wage of a worker is determined by the average recruiting expenses incurred by firms, $v \gamma / u$. Substitute the worker's reservation wage given by (100) into the outcome of the Nash bargaining (98) to obtain

$$
w=\varpi \varphi+\varpi\left(\frac{r+\delta}{\rho+\delta}\right) \theta \gamma .
$$

The novelty relative to the Mortensen-Pissarides model is the term $(r+\delta) /(\rho+\delta) \leq 1$, which multiplies the average recruiting expenses of firms. The rate at which workers discount their future wages is higher than the rate at which firms discount their future profits. This reduces the threat of the worker not to take the job and reduces the value of the negotiated wage.

In order to obtain market tightness, we substitute $w$ into the vacancy-supply condition:

$$
\frac{\gamma}{q(\theta)}+\frac{\varpi \theta \gamma}{\rho+\delta}=\frac{(1-\varpi) \varphi}{r+\delta}
$$

As before this equation gives a negative relationship between $\theta$ and $r$. 


\section{A2. Heterogenous private assets}

In the following we provide some detailed derivations for the necessary conditions, (73) and (74), to the OTC-trader's optimal portfolio problem in the presence of heterogeneous assets. We will consider the case where the number of types for private assets is finite, $\omega \in\{1, \ldots, \Omega\}$. Let $a^{\omega}$ denote the trader's holdings of asset $\omega$ and $r^{\omega}$ the rate of return of asset $\omega$. The problem of the OTC-trader with an initial portfolio, $\left(a_{0}^{1}, \ldots, a_{0}^{\Omega}, g_{0}\right)$, is

$$
\begin{aligned}
W\left(a_{0}^{1}, \ldots, a_{0}^{\Omega}, g_{0}\right) & =\max _{\left\{a^{\omega}(t), \varepsilon^{\omega}(t)\right\}, g(t), c(t)}\left\{\mathbb{E} \int_{0}^{T_{1}} e^{-\rho t} c(t) d t+e^{-\rho T_{1}} Z\left[a^{1}\left(T_{1}\right), \ldots, a^{\Omega}\left(T_{1}\right), g\left(T_{1}\right)\right]\right\} \\
\text { s.t. } \quad \dot{g} & =\sum_{\omega \in \Omega} r^{\omega} a^{\omega}+r^{g} g-\varepsilon^{\omega}-c-\Upsilon \\
\dot{a}^{\omega} & =\varepsilon^{\omega} \text { for all } \omega \in\{1, \ldots, \Omega\} \\
a^{\omega}(0) & =a_{0}^{\omega} \text { for all } \omega \in\{1, \ldots, \Omega\} \\
g(0) & =g_{0} .
\end{aligned}
$$

The current value Hamiltonian associated with this problem is

$$
\begin{aligned}
H\left(c, a^{1}, \ldots, a^{\Omega}, g, \xi\right)= & c+\alpha Z\left(a^{1}, \ldots, a^{\Omega}, g\right)+\xi^{g}\left(\sum_{\omega \in \Omega} r^{\omega} a^{\omega}+r^{g} g-\varepsilon^{\omega}-c-\Upsilon\right) \\
& +\sum_{\omega=1}^{\Omega} \xi^{\omega} \varepsilon^{\omega} .
\end{aligned}
$$

The Maximum Principle implies $\xi^{g}=\xi^{\omega}=1$ for all $\omega$. So the value function, $W$, is linear with respect to each of its arguments. Moreover, the differential equations for the co-state variables imply

$$
\begin{aligned}
& \rho+\alpha=\alpha Z_{g}\left(a^{1}, \ldots, a^{\Omega}, g\right)+r^{g} \\
& \rho+\alpha=\alpha Z_{\omega}\left(a^{1}, \ldots, a^{\Omega}, g\right)+r^{\omega} \quad \text { for all } \omega \in\{1, \ldots, \Omega\} .
\end{aligned}
$$

Suppose that a trader in an OTC match can pledge a fraction $\lambda^{\omega}$ of his holdings of asset $\omega$. Moreover, private assets are only acceptable in a fraction, $\mu^{p}$, of all matches. The trader's value function when matched solves

$$
Z\left(a^{1}, \ldots, a^{\Omega}, g\right)=\frac{\mu^{p} \max _{y \leq \ell}\left\{f\left(y^{p}\right)-y^{p}\right\}+\left(1-\mu^{p}\right) \max _{y \leq g}\left\{f\left(y^{g}\right)-y^{g}\right\}}{2}+W\left(a^{1}, \ldots, a^{\Omega}, g\right),
$$

where $\ell=\sum_{\omega=1}^{\Omega} \lambda^{\omega} a^{\omega}+g$. Using (109) the necessary conditions, (107) and (108), can be reexpressed as

$$
\begin{aligned}
& \rho-r^{g}=\sigma\left\{\mu^{p}\left[f^{\prime}\left(y^{p}\right)-1\right]+\left(1-\mu^{p}\right)\left[f^{\prime}\left(y^{g}\right)-1\right]\right\} \\
& \rho-r^{\omega}=\sigma \mu^{p} \lambda^{\omega}\left[f^{\prime}\left(y^{p}\right)-1\right] \quad \text { for all } \omega \in\{1, \ldots, \Omega\} .
\end{aligned}
$$

These two conditions correspond to (73) and (74). 